\title{
DIII-D Diagnostic Systems
}

R. L. Boivin, J. L. Luxon, M. E. Austin, N. H. Brooks, K. H. Burrell, E. J. Doyle, M. E. Fenstermacher, D. S. Gray, M. Groth, C.-L. Hsieh, R. J. Jayakumar, G. R. McKee, C. J. Lasnier, A. W. Leonard, R. A. Moyer, T. L. Rhodes, J. C. Rost, D. L. Rudakov, M. J. Schaffer, E. J. Strait, D. M. Thomas, M. VanZeeland, J. G. Watkins, W. P. West, C. P. C. Wong

October 18, 2005

Fusion Science and Technology 
This document was prepared as an account of work sponsored by an agency of the United States Government. Neither the United States Government nor the University of California nor any of their employees, makes any warranty, express or implied, or assumes any legal liability or responsibility for the accuracy, completeness, or usefulness of any information, apparatus, product, or process disclosed, or represents that its use would not infringe privately owned rights. Reference herein to any specific commercial product, process, or service by trade name, trademark, manufacturer, or otherwise, does not necessarily constitute or imply its endorsement, recommendation, or favoring by the United States Government or the University of California. The views and opinions of authors expressed herein do not necessarily state or reflect those of the United States Government or the University of California, and shall not be used for advertising or product endorsement purposes. 


\title{
DIII-D DIAGNOSTIC SYSTEMS
}

\author{
by \\ R.L. BOIVIN, J.L. LUXON, M.E. AUSTIN, N.H. BROOKS, K.H. BURRELL, E.J. DOYLE, \\ M.E. FENSTERMACHER, D.S. GRAY, M. GROTH, C.-L. HSIEH, R.J. JAYAKUMAR, \\ G.R. McKEE, C.J. LASNIER, A.W. LEONARD, R.A. MOYER, T.L. RHODES, \\ J.C. ROST, D.L. RUDAKOV, M.J. SCHAFFER, E.J. STRAIT, D.M. THOMAS, \\ M. VanZEELAND, J.G. WATKINS, W.P. WEST, and C.P.C. WONG
}




\section{DISCLAIMER}

This report was prepared as an account of work sponsored by an agency of the United States Government. Neither the United States Government nor any agency thereof, nor any of their employees, makes any warranty, express or implied, or assumes any legal liability or responsibility for the accuracy, completeness, or usefulness of any information, apparatus, product, or process disclosed, or represents that its use would not infringe privately owned rights. Reference herein to any specific commercial product, process, or service by trade name, trademark, manufacturer, or otherwise, does not necessarily constitute or imply its endorsement, recommendation, or favoring by the United States Government or any agency thereof. The views and opinions of authors expressed herein do not necessarily state or reflect those of the United States Government or any agency thereof. 


\section{DIII-D DIAGNOSTIC SYSTEMS}

by

R.L. BOIVIN, J.L. LUXON, M.E. AUSTIN, ${ }^{*}$ N.H. BROOKS, K.H. BURRELL, E.J. DOYLE, ${ }^{\dagger}$ M.E. FENSTERMACHER, ${ }^{\ddagger}$ D.S. GRAY, ${ }^{\Delta}$ M. GROTH, ${ }^{\ddagger}$ C. -L. HSIEH, R.J. JAYAKUMAR, ${ }^{\ddagger}$ G.R. McKEE," C.J. LASNIER, ${ }^{\ddagger}$ A.W. LEONARD, R.A. MOYER, ${ }^{\Delta}$ T.L. RHODES, ${ }^{\dagger}$

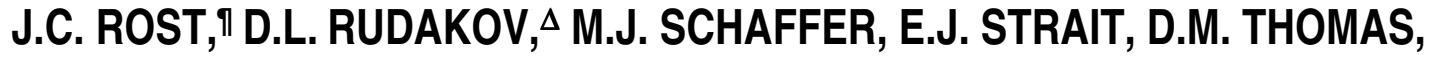
M. VanZEELAND, J.G. WATKINS, $\$$ W.P. WEST, and C.P.C. WONG

This is a preprint of a paper to be submitted for publication in a special issue of Fusion Science and Technology.

*University of Texas, Austin, Texas.

tUniversity of California - Los Angeles, Los Angeles, California.

‡Lawrence Livermore National Laboratory, Livermore, California.

$\Delta$ University of California - San Diego, La Jolla, California.

\#University of Wisconsin, Madison, Wisconsin.

TMassachusetts Institute of Technology, Cambridge, Massachusetts.

§andia National Laboratory, Albuquerque, New Mexico.

Work supported by

the U.S. Department of Energy

under DE-FC02-04ER554698, DE-FG03-97ER54415, DE-FG03-01ER54615, W-7405-ENG-48, DE-FG02-04ER54758, DE-FG03-96ER54373,

DE-FG02-04ER54235, and DE-AC04-94AL85000

\section{GENERAL ATOMICS PROJECT 30200 MARCH 2004}




\section{ABSTRACT}

The DIII-D tokamak, located at General Atomics in San Diego, California, has long been recognized as being one of the best diagnosed magnetic fusion experiments. Composed of more than 50 individual systems, the diagnostic set takes advantage of a high number of large aperture access ports. These instruments are used in support of basic control of the tokamak and experiments in the transport, stability, boundary and heating and current drive science areas. These systems have contributed to the success of the Advanced Tokamak (AT) program, in addition to the many contributions to our physics understanding and real-time control of fusion-relevant plasmas. Numerous novel techniques have been developed, tested, and fielded on DIII-D including new approaches required for a Burning Plasma Experiment (BPX). Details of the diagnostic systems will be described along with some illustrative recent results. 


\section{INTRODUCTION}

The DIII-D plasma diagnostic set comprises more than 50 instruments built and operated by many groups from different institutions. This ensemble of instruments is one the best set of any tokamak in the world and routinely produces the high quality data required to support the DIII-D Scientific Research Program. Listed in Table I is a summary of the diagnostics installed in the DIII-D tokamak.

The effectiveness of this diagnostic system is the result of a comprehensive, long-standing collaborative effort between universities, national laboratories, and industries to integrate diagnostics designed, developed and tested at those institutions in order to maximize the scientific productivity of the DIII-D national facility. The DIII-D diagnostics set includes extensive divertor and edge measurement capability, plasma core profile measurements of density, temperature and plasma current and an extensive suite of fluctuation diagnostics.

DIII-D diagnostics coupled with ongoing development of analysis and modeling tools have led to remarkable advances in plasma performance and in the understanding of the underlying physics. Extensive magnetic, x-ray, current profile, and radiated power diagnostics have led to detailed studies of the role of the equilibrium configuration in stability and transport. They have enabled precise real time control of the plasma configuration and, in a number of cases, plasma instabilities. Comprehensive diagnosis of the plasma core has resulted in a more fundamental understanding of transport and the associated role of turbulence. This, coupled with enhanced diagnosis of the edge region, has enabled a deeper comprehension of the role of the pedestal in transport and stability of the discharge. A unique set of boundary region diagnostics has brought deeper insight in the complex dynamics found in the divertor region, and its connection to the chamber walls. Much of this work has become the foundation for designing next generation devices.

The effective use of diagnostics in the ever more complex analysis of tokamak discharges requires precise signal resolution, spatial calibration and temporal resolution along with high reliability. This is a hallmark of the DIII-D program. Diagnostic signals are calibrated to high precision and the spatial location of diagnostics measurement points is determined to a fraction of a centimeter and often to a millimeter. The cross 
comparison of diagnostic information, both through direct comparison and using complex models, with the current theories remains a vigorous aspect of research on DIII-D.

Table I. Summary of diagnostics installed in DIII-D

\section{Electron Temperature and Density}

Multipulse Thomson scattering

ECE Michelson interferometer

ECE radiometer

Multichannel vibration compensated

(infrared) interferometer

Microwave reflectometer

Microwave interferometer

Ion Temperature and Velocity

Charge exchange recombination spectroscopy

\section{Core Impurity Concentration}

VUV survey spectrometer (SPRED dual range)

Visible Bremsstrahlung array

\section{Radiated Power}

Bolometer arrays

Fast bolometers

\section{Divertor Diagnostics}

Visible spectrometer

Tangential TV (visible)

Tangential TV (VUV)

Infrared cameras

Graphite foil bolometers

Fast neutral pressure gauges

Penning gauges

Baratron gauge

Langmuir probes

Moveable scanning probe

Tile current monitors

Tile calorimetry

Magnetic Properties

Rogowski loops

Voltage loops

$\mathrm{B}_{\theta}$ loops

Diamagnetic loops

External $\mathrm{B}_{\mathrm{r}}$ loops

Internal $\mathrm{B}_{\mathrm{r}}$ loops

External $\mathrm{B}_{\theta}$ loops

\section{Plasma Edge/Wall}

Plasma TV

IR camera

Visible filter scopes

Moveable Langmuir probe
8 lasers, 44 radial points

Horizontal midplane profiles

Horizontal midplane, 40 channels

3 vertical chords, 1 radial chord

Midplane edge profiles

1 chord

16 vertical channels; 24 horizontal channels

Radial midplane view

Radial profile at midplane, 16 channels

2 poloidal arrays, 48 channels each

Poloidal array, 30 channels

12 channels, upper and lower divertor

2-D image of lower divertor

2-D image of lower divertor

4 cameras

12 locations

6 locations, 5 in divertors, 1 main chamber

Under divertor baffle (upper and lower)

Under divertor baffle

26 probes lower divertor, 28 probes upper divertor and centerpost

Scannable through lower divertor outer leg (X-point)

34 lower divertor, 6 upper

1 channel

3 toroidal locations

41 poloidal locations and 30 saddle loops

44 poloidal locations

9 toroidal locations

3 arrays, 30 loops

3 arrays, 10 loops

8 toroidal locations

4 cameras, radial view, rf antennae, main chamber

Inner wall and ceiling views, floor

24 locations

Scannable across outer midplane 


\section{Fluctuations/Wave Activities}

Beam emisson spectroscopy

Microwave reflectometers

Far infrared scattering

Phase contrast imaging

Mirnov coils

Li beam injector

$\mathrm{X}$-ray imaging system

RF probes

Scanning probe (midplane)

\section{Particle Diagnostics}

Neutral particle analyzer

Fast neutron scintillation counters

Natural diamond detector

Lost fast ion detector

Neutron detectors

Plasma Current Profiles

Motional Stark polarimeter

Li beam injector

(edge current profile)

\section{Miscellaneous}

Hard $\mathrm{x}$-ray monitors

Synchrotron (IR) radiation detector

Torus pressure gauges

Residual gas analyzer

\author{
2-D, 32 channels \\ 2 radial systems \\ Radial view \\ Vertical view, 16 channels \\ Toroidal, poloidal, and radial arrays, 60 coils \\ Radial beam with 32 vertical viewing channels \\ 100 channels, 5 arrays \\ 5 plasma-facing antennae, 6 recessed loops \\ Temperature, potential
}

3 vertical views

2 radial channels

1 vertical chord

2 toroidal locations

4 toroidal locations

45 channels, 4 half-energy channels

Radial beam with 32 vertical viewing channels

4 toroidal locations

2 tangential chords on midplane

Diagnostics are taking an ever-increasing role in the feedback control of tokamak operation and this is expected to become more important in burning plasma experiments. Such control results in more stable and reliable operation and can extend the operating space. Magnetic diagnostics are essential to the precise control of the plasma shape and position, and evolving techniques continue to improve precision. The total plasma energy has been controlled using the signal from the diamagnetic loop to control the neutral beam or electron cyclotron power input. The magnetic diagnostics role of characterizing the fluctuations and instabilities in the plasma has been extended to the control of instabilities by linking it to the localized application of electron cyclotron current drive. Measurements of the electron temperature from the electron cyclotron emission (ECE) diagnostic have been used to control the electron temperature using electron cyclotron heating. New diagnostics are being developed to target specific needs of next generation devices. The fast wave reflectometer measures the species mix of the plasma ions and represents a technique for measuring the $\mathrm{D}$ - $\mathrm{T}$ ratio in burning plasmas. All of these techniques are discussed in the main body of this paper and references are cited therein.

Many of the diagnostic techniques used on DIII-D are expected to be used in a burning plasma device [1-4]. In addition, new diagnostic techniques are being pursued in 
some areas critical to burning plasma experiments. A good example of this is the fast wave reflectometry discussed later in this report.

Many of the diagnostics fielded on DIII-D will be introduced in this paper along with their key uses. The reader can find further details, such as construction, design, and calibration aspects in the references provided. 


\section{DIAGNOSTICS RELATED TO TRANSPORT STUDIES}

The study of plasma properties has been the focus of many experiments in the last 40 years. While many of the original measurements were single point, single time slices of plasma parameters, the diagnostics have evolved dramatically in order to provide the basis for understanding the dynamics in plasma transport. Now, for example in DIII-D, requirements include the measurements of the profiles of ion temperature and ion density [e.g. charge-exchange recombination (CER)], electron temperature [e.g. Thomson, ECE] and electron density (e.g. Thomson, interferometer, reflectometer), rotation profiles (e.g. CER), impurity content and distribution [e.g. CER, survey, poor resolution, extended domain (SPRED), visible bremsstrahlung]. However, recently, these studies have incorporated detailed measurements of plasma fluctuations and turbulence, which are believed to be the cause of anomalous transport. These measurements include, for example, density fluctuations diagnostics such as the beam-emission spectroscopy (BES), laser and microwave scattering, phase contrast imaging (PCI) and reflectometer. Those systems are described below.

\section{A. Charge exchange recombination}

Charge exchange excitation of spectral lines in tokamak plasmas was first observed about 25 years ago [5]. Since then, it has become the basis for one of the standard ion diagnostic techniques on magnetic fusion devices equipped with neutral beam injection [6-22]. Exploiting Doppler broadening and Doppler shift of excited spectral lines, CER spectroscopy gives the ion temperature $T_{\mathrm{i}}$, toroidal rotation speed $V_{\phi}$, and poloidal rotation speed $V_{\theta}$ of the ion species being measured. Furthermore, combining these measurements with the radial force balance equation [14,15,23-25] allows calculation of the radial electric field $E_{\mathrm{r}}$. Because the light emitted due to charge exchange excitation is localized to the space occupied by the neutral beam, measurements can be made with good spatial resolution. The basic layout of the CER system is shown in Fig. 1.

Vertical views of the edge plasma provided the key to an extremely important discovery. Using data from these views, Groebner et al. [14,15,26] demonstrated a significant change in the edge $E_{\mathrm{r}}$ at the time of the $\mathrm{L}$ to $\mathrm{H}$ transition. This change took place in a very narrow region near the plasma edge. Coupled with theoretical work 
developed in parallel, this was the beginning of the work on $E \times B$ shear stabilization of turbulence [27-29].

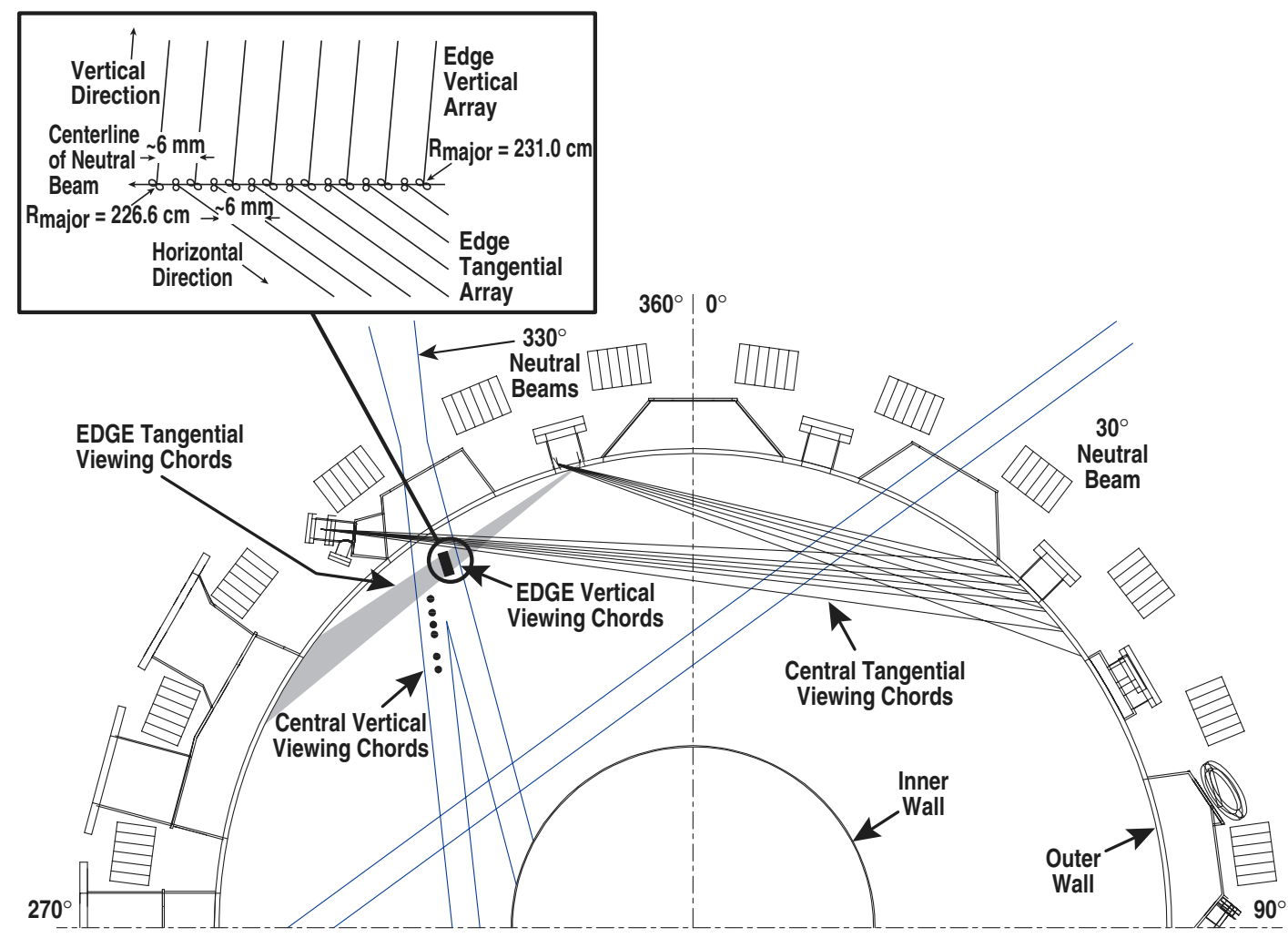

Fig. 1. Schematic view of the available chords on the CER system (2003).

The desire to study the edge of discharges with high confinement (H-mode) in detail motivated installation of eight additional vertical and eight tangential view chords dedicated to studying the plasma edge [16]. The initial $1.5 \mathrm{~cm}$ spacing between views was quickly reduced to $6 \mathrm{~mm}$ when the first observations showed that the scale length of the H-mode edge pedestal was even shorter than first anticipated.

The CER diagnostic system was later extended to measure the absolute density of various impurity species. This work included the determination of the pressure gradient contribution to $E_{\mathrm{r}}$ in the plasma core and investigation of impurity content and impurity transport [30,31]. This allows determination of $E_{\mathrm{r}}$ in the plasma core and understanding of its evolution when transport barriers develop [27,28]. In addition, helium transport studies based on this analysis demonstrated that helium exhaust in ELMing H-mode plasmas is sufficiently fast for helium ash removal in tokamak fusion reactors [32,33].

Calibration of the diagnostic is extremely important. In order to use the Doppler shifts of spectral lines to measure the poloidal and toroidal plasma velocities, one has to know the position on the detectors which correspond to the zero of rotation. Systematic 
errors introduce errors in the inferred velocity. To address this issue, a system was developed that inserts a diffuse well-characterized neon light source in the optical path to obtain a wavelength calibration spectrum after every discharge [34]. Using oppositely directed viewchords, we also independently determined the wavelength of the C VI $5290.5 \AA$ A line when excited by charge exchange from which the zero rotation speed point is derived [34].

The diagnostic allows us to follow plasma behavior with short integration time and rapid repetition rate. Figure 2 shows the variation in edge carbon temperature and toroidal rotation velocity during the time when a Type I edge localized mode occurs. These data were taken with 274 microsecond integration time and have quite good signal to noise, as can be seen by the minimal scatter in the results. The number of spectra measured during the discharge is limited only by computer memory. The present system configuration allows 1000 measurements for each chord during a discharge.

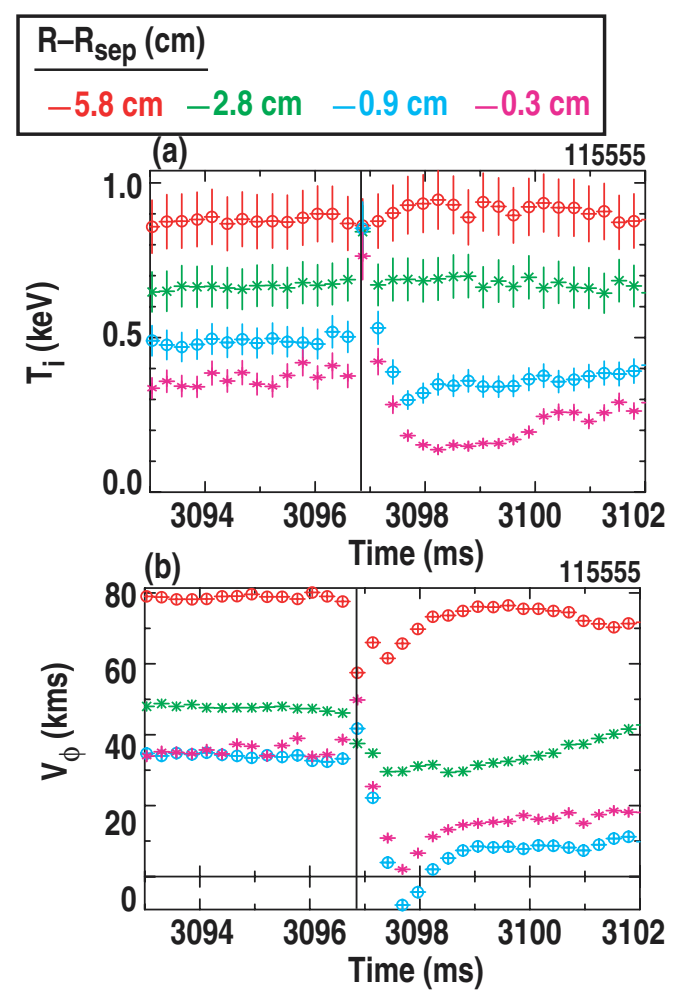

Fig. 2. Plot of the edge plasma behavior during the time that an edge localized mode occurs at the plasma edge (a) ion temperature, (b) carbon toroidal rotation speed. The measurement locations relative to the magnetic separatrix at the plasma edge are given at the top (a). Each data point is taken with 274 microsecond integration time.

The excellent spatial resolution in quiescent $\mathrm{H}$-mode discharges is illustrated in Fig. 3 [35]. These data were produced by sweeping the edge of the plasma past the 
detectors to produce additional spatial points. The radial resolution of the individual viewchords is about $5 \mathrm{~mm}$ and the profiles can be resolved to at least this accuracy.
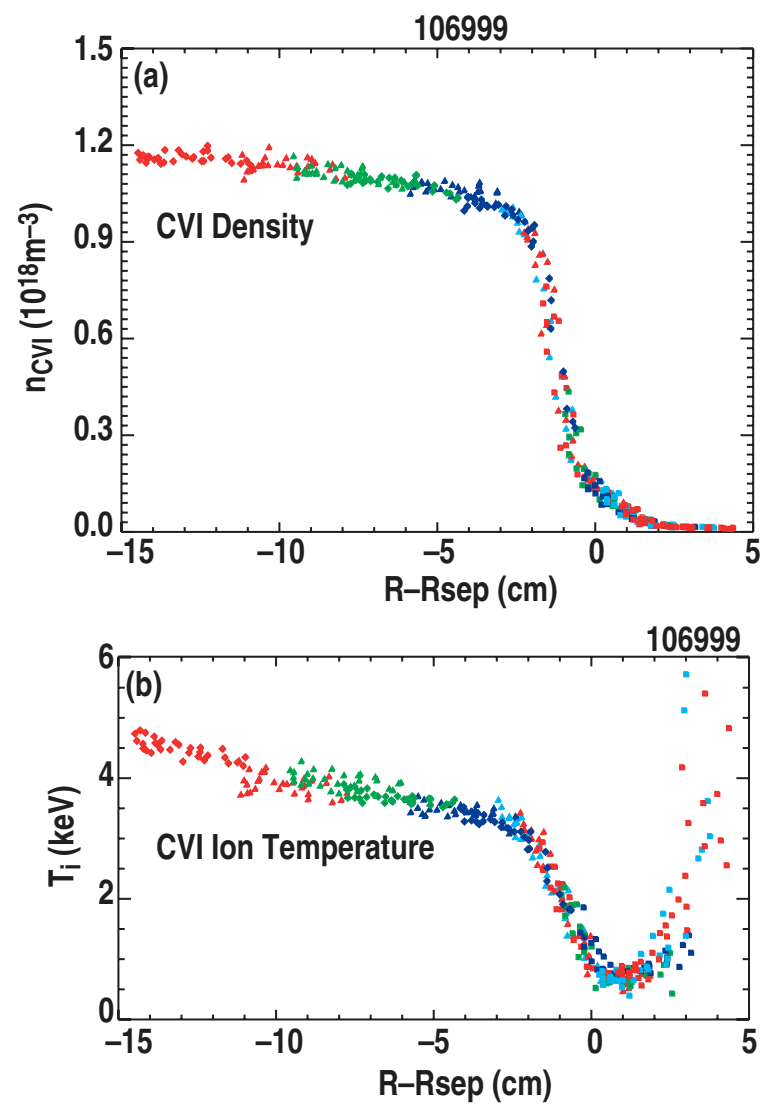

Fig. 3. (a) Density and (b) temperature of fully stripped carbon $\left(\mathrm{C}^{+0} \mid\right.$ from charge exchange spectroscopy plotted as a function of distance from the separatrix at the midplane on the low field side of the plasma. The plasma edge is swept radially to improve spatial resolution. The separatrix location at each measurement time is determined from MHD equilibrium analysis [35]. The agreement in the regions of overlap demonstrates that the edge plasma does not vary during the sweep.

\section{B. Extreme ultraviolet survey spectrometer (SPRED)}

Extreme ultraviolet (EUV) spectroscopy is a key element of monitoring the impurities in DIII-D plasmas. Low Z impurities, typically C, B, and O, are dominant, due to the fact that the DIII-D plasma facing wall is $>95 \%$ graphite which is frequently overcoated with thin boron films. The low charge states of the low-Z elements exist only in the edge region of the plasma. Their strong emission lines lie in the wavelength range 30-110 nm. In the core region of the plasma, B, C, and O are fully stripped. Detection of these species in the core relies on the prompt emission from the hydrogenic species that occurs following CER with neutral deuterium atoms in a heating beam. CER emission lines from low $\mathrm{n}$ transitions of $\mathrm{B}^{+4}, \mathrm{C}^{+5}$, and $\mathrm{O}^{+7}$ lie in the range $10-30 \mathrm{~nm}$. Metallic 
impurities, mostly $\mathrm{Fe}, \mathrm{Ni}$, and $\mathrm{Cu}$, arise from the Inconel vacuum vessel and the copper rf antenna straps. The brightest lines from these impurities arise from the lithium- and beryllium-like ionization states that are concentrated in the core. These emission lines are observed between 11 and $25 \mathrm{~nm}$.

A dual-range SPRED spectrometer [36] with two optical systems arranged back-to-back is used as a routine monitor of the low- $Z$ and medium- $Z$ impurities on DIII-D. Each of the optical systems is comprised of its own entrance slit, grating and detector. The dual range system covers the EUV spectral ranges 10-29 nm and 25-110 $\mathrm{nm}$. The detector in each optical system consists of a $50 \mathrm{~mm}$-diameter microchannel plate intensifier and fast optical multichannel analyzer (FOMA) linear diode array camera [37]. The input of the intensifier is coated with CsI; the visible output is produced by electron impact on a P20 phosphor deposited on the face of a fiberoptic reducer which serves as the vacuum window. The FOMA camera utilizes a 1024-pixel Reticon array. The integration time for each camera can be varied from $1 \mathrm{~ms}$ to $1000 \mathrm{~ms}$; memory permits storage of 2048 frames per shot. The near parallel sightlines of the two systems are tangential to the plasma major radius, crossing one of the heating beams a small distance outside of the magnetic axis of typical plasmas. The charge exchange recombination lines from the low-Z impurities are very prominent in most discharges.

\section{Visible Bremsstrahlung array}

The "effective charge" of the plasma is an important parameter in characterizing a deuterium plasma containing small amounts of impurities in ionic charge states much higher than singly ionized. The effective charge, $Z_{\text {eff }}$, determines the electrical resistivity of the plasma, the penetration of neutral beams, the radiation loss and other important characteristics. $Z_{\mathrm{eff}}$ is measured on DIII-D from the enhancement in visible continuum emission produced by free-bound transitions between electrons and impurity ions over that due only to free-free transitions between electron and deuterium ions [38]. The hardware used on DIII-D is similar to that on other tokamaks: an array of photomultipliers view the plasma in $3 \mathrm{~nm}$ passband centered at the line-free spectral region centered at $523 \mathrm{~nm}$, using interference filters. Sixteen tangential viewchords span the horizontal midplane of the plasma from inner wall to outer, with more than half of the chords looking into razor blade viewing dumps to avoid reflections from brighter regions than that spanned by the direct view [39]. 


\section{Thomson scattering diagnostic}

The use of YAG laser for multi-pulse Thomson scattering measurement was first demonstrated in ASDEX [40], which demonstrated their potential. Shortly thereafter a similar system was designed, built and operated on DIII-D [40-44]. The system has eight YAG lasers providing approximately $0.6 \mathrm{~J}$ per pulse and operating at $20 \mathrm{~Hz}$. The lasers' lights are guided through a beam path of about $35 \mathrm{~m}$ in length to the plasma chamber. The alignment system is aided by a series of CCD cameras located along the path and a target system that can be lowered into the vessel under vacuum, in order for the collection system to view the alignment HeNe laser. In order to minimize the stray light from the YAG laser, specially designed beam baffle assemblies at the beam entrance and exit of the vessel are incorporated. Because of the low stray light level, we are able to calibrate the system using Rayleigh scattering. As a result, density measurements using the Thomson scattering system are normally accurate to within $10 \%$.

A wide-angle collection optics ( $\mathrm{F} / 5)$ collects light scattered along the laser path and images it onto an array of 44 fiber bundles. The mounting position of the fiber bundle is adjustable; for instance, more channels usually view the plasma boundary region. A polychromator [42] disperses the light into seven wavelength bands defined by individual filters. The filters close to the YAG line need not only to reject the laser light well but also to have the bandwidth sufficiently narrow for low temperature measurements. The detector is an avalanche photodiode with an internal gain of about 70 . We also measure and correct for the plasma background light since it plays a dominant role in the signal fluctuation. The data acquisition has a turn-around time of less than $100 \mu$ s. We have operated lasers segmentally, $100 \mu$ s apart, for studying fast plasma events, for instance, plasma disruptions.

Early on, the core Thomson scattering system showed the existence of edge density and temperature pedestals in high confinement (H-mode) plasmas. Later, in order to better characterize the divertor plasmas, we installed a system in the lower divertor region [45]. These measurements have been essential to the understanding of divertor operation and to the development of a divertor transport model. We have obtained the first measurements of $n_{\mathrm{e}}$ and $T_{\mathrm{e}}$ in the divertor region. Eight measurement locations are distributed vertically up to $21 \mathrm{~cm}$ above the divertor plate at $R=1.43 \mathrm{~m}$. Two-dimensional distributions have been obtained by sweeping the divertor plasma across the measurement locations [46], and are shown in Fig. 4. We find that in ELMing $\mathrm{H}$-mode plasmas, the electron density, $n_{\mathrm{e}}$, temperature, $T_{\mathrm{e}}$, and pressure are relatively 
constant along field lines from the $\mathrm{X}$-point to the divertor plate, especially near the separatrix field line.

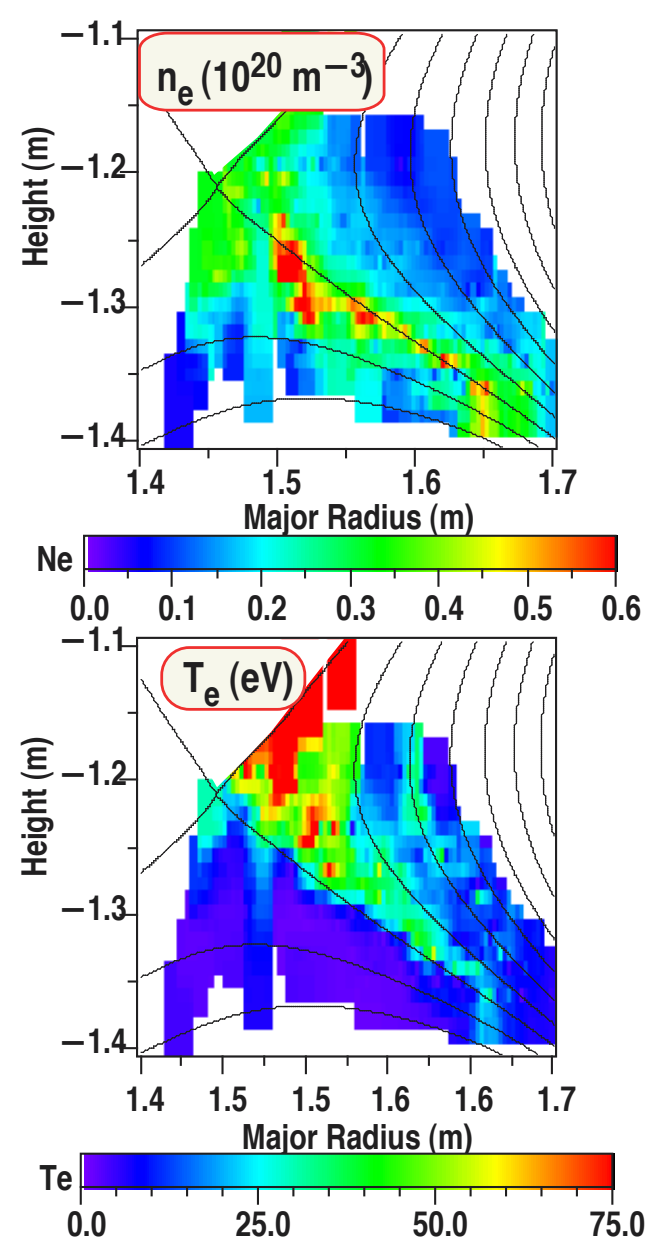

Fig. 4. Two-dimensional mapping of the electron density and electron temperature in the lower divertor. The mapping was obtained by sweeping the lower X-point of the discharge over the divertor Thomson scattering chords. Also shown is the equilibrium flux surfaces obtained from the code EFIT.

\section{E. $\mathrm{CO}_{2}$ vibration compensated interferometer}

Dual laser interferometry provides integral measurements of the electron density on DIII-D [47-50]. The basis for a dual wavelength interferometer is that the use of the two wavelengths allows the distinction between fringe shifts due to plasma and fringe shifts due to mirror motion. The current multi-channel quadrature heterodyne system consists of three vertical chords and one radial chord with each chord using both a $\mathrm{CO}_{2}$ laser $(10.6 \mu \mathrm{m})$ and a HeNe laser $(0.632 \mu \mathrm{m}$ for the vertical chords and $3.9 \mu \mathrm{m}$ for the radial).

Dedicated phase detection and calculation circuitry provides real-time density and vibration measurements for feedback control of the density while simultaneously 
reducing the amount of computer memory and analysis required for each shot. A distinguishing feature of this system is the combination of high speed $(1 \mathrm{MHz})$, high resolution $\left( \pm 2 / 256 \mathrm{CO}_{2}\right.$ fringe, or $\left.\pm 5 \times 10^{17} \mathrm{~m}^{-3}\right)$, and wide range $( \pm 8193$ fringes $)$ it offers [50]. This makes it possible to follow rapid changes in density resulting from such events as pellet injection, edge localized modes (ELMs), and plasma disruptions. Additionally, error checking in the form of a coded voltage output provides the ability to diagnose signal level errors as well as probable fringe count errors for both interferometers [50]. Recently, a post-shot error correction scheme, which exploits the fact that data are acquired after the plasma density has decayed to zero, has been implemented and further improves the overall system accuracy. This interferometer is capable of operating continuously for weeks at a time with very little adjustment - an important capability when implementation on next step devices such as ITER is considered.

\section{F. Electron cyclotron emission}

The ECE diagnostics set on DIII-D is comprised of two main instruments: a scanning Michelson interferometer [51] and a 40 channel heterodyne radiometer [52]. Data from both of these systems are made available for almost every discharge and provide a complementary set of information on the DIII-D plasma electron temperature. The Michelson interferometer provides a measurement of the ECE spectrum from $60-500 \mathrm{GHz}$, covering harmonics 2-6 of the electron cyclotron frequency, with a time resolution of $25 \mathrm{~ms}$. It is used for calibration of the radiometer and to monitor the electron distribution function. The ECE radiometer system provides a time resolved $T_{\mathrm{e}}$ measurement at 40 specific locations in the plasma. Spatial resolution is between 2 and $4 \mathrm{~cm}$, dependent on plasma conditions. The channel bandwidth is presently being upgraded from $1 \mathrm{GHz}$ to $400 \mathrm{MHz}$. At present the time resolution is set at $1 \mu \mathrm{s}$. The radiometer is used to monitor small scale perturbations in the electron temperature profile, such as caused by MHD modes and heat pulses, and is the primary source of $T_{\mathrm{e}}(r, t)$ measurement for electron transport and heating efficiency studies.

An example of a new use for the ECE radiometer signals on DIII-D is for feedback control of electron cyclotron or neutral beam heating to attain a specific temperature profile in the plasma. Figure 5 shows a discharge with feedback control of electron cyclotron heating $(\mathrm{ECH})$ by using a single ECE channel to give a sawtoothing $T_{\mathrm{e}}$ variation at the half radius. In the future, a 32 channel interface to the DIII-D plasma control system will be used for more extensive temperature and current profile regulation. 


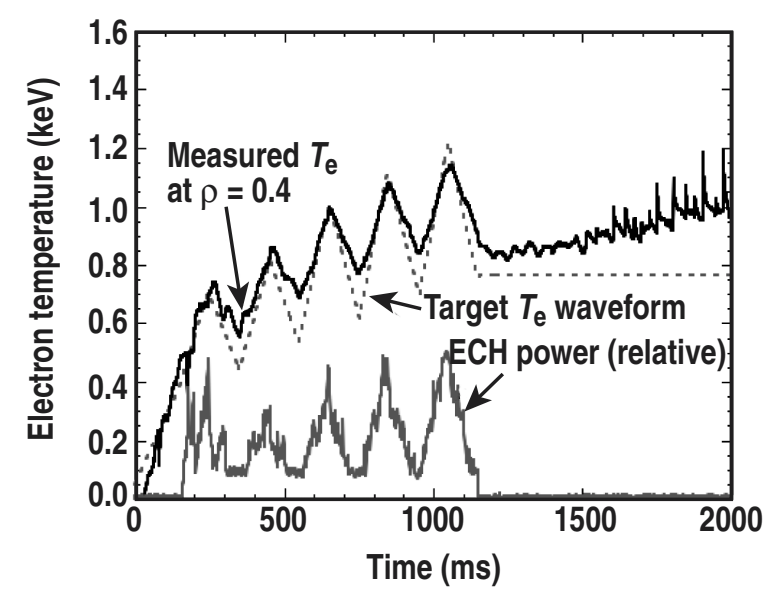

Fig. 5. Plot showing sawtooth variation of electron temperature obtained from feedback control of ECH using an ECE $T_{\mathrm{e}}$ signal.

\section{G. Fast wave reflectometry}

Ion species measurements in a tokamak plasma have several uses. A direct measure of the ion species mix in the interior of the plasma can be utilized to help to achieve and to maintain deuterium and tritium density equilibrium $\left(n_{\mathrm{D}} \sim n_{\mathrm{T}}\right)$, maximizing fusion reactions in a burning plasma experiment. A number of wave heating schemes in the ion cyclotron range of frequencies (ICRF) depend on the relative concentrations of ions with different charge-to-mass ratios, so measurements of the concentrations are required to understand and control the heating profile. In transport studies, measurement of the density profiles of ions with different charge-to-mass ratios can help to illuminate the mechanisms of particle transport. A superheterodyne reflectometer provides a direct and inexpensive measurement of the species mix composition of different charge to mass ratio ions. Using the cold plasma dispersion relation, the ion-ion hybrid cutoff frequency is uniquely determined by the density ratio and cyclotron frequencies of the two different species. A reflectometer diagnostic that uses an ICRF wave can thus be used to measure the ion species mix [53].

In DIII-D, the phase of a $20 \mathrm{MHz}$ wave that travels from the launching point (usually, inner wall) to the cutoff layer and then back to the receiving antenna is used to provide a direct measure of the hydrogen:deuterium species mix. The fast Alfvén wave is launched from the high field side of the tokamak, in this case during a hydrogen puffing experiment. The results suggest that a wave launched from the high field side is able to tunnel through the resonance layer and reflect back to the receiving antenna. Figure 6 shows the hydrogen concentration inferred along with corroborative values obtained from two independent diagnostics. In this discharge, reflection first occurs $4 \mathrm{~ms}$ after the 
hydrogen gas puff begins, indicating that, the ion-ion-hybrid cyclotron layer entered the plasma at this time. This observation provides a calibration phase value for the reflectometer signal, so the subsequent evolution of the hydrogen concentration $f_{H}$, is determined from the reflectometer signals alone. All three diagnostic techniques record a significant increase in hydrogen concentration $\mathrm{f}_{\mathrm{H}}$ when the hydrogen gas puff begins at $300 \mathrm{~ms}$, and are in good agreement [54].

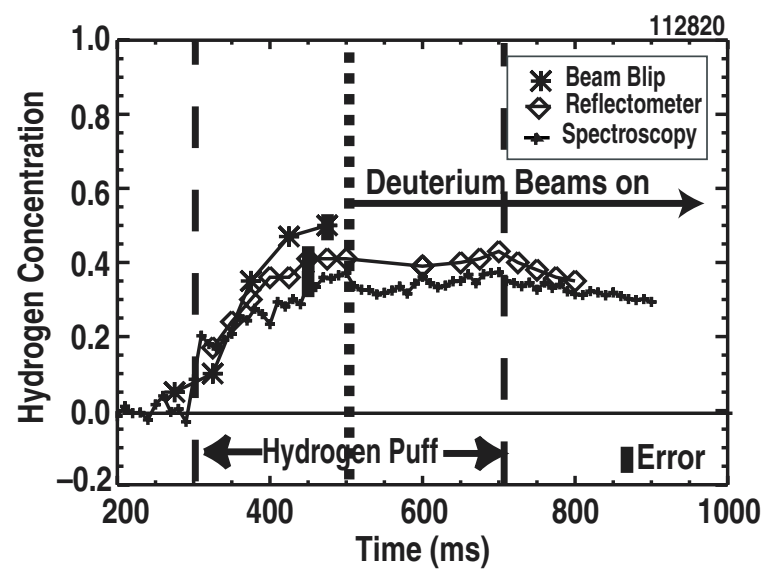

Fig. 6. Time evolution of the hydrogen concentration inferred from the beam-blip neutron diagnostic (*), the ion-ion hybrid reflectometer diagnostic (diamonds), and the $H_{\alpha} D_{\alpha}$ spectroscopic diagnostic (+). Typical random error bars for each diagnostic are shown. A hydrogen gas puff begins at $300 \mathrm{~ms}$ and ends at $700 \mathrm{~ms}$; deuterium beam injection begins at $500 \mathrm{~ms}$. To relate the beam-blip and spectroscopic diagnostics to $f_{\mathrm{H}}$, a constant carbon density of $1.6 \times 10^{12} \mathrm{~cm}^{-3}$ is assumed. $B_{\mathrm{T}}=1.9 \mathrm{~T}, \Omega / 2 \pi=19.5 \mathrm{MHz}$, LFS launch.

\section{H. Beam emission spectroscopy}

A BES density fluctuation diagnostic system has been deployed, operated, and is presently being extensively upgraded at the DIII-D tokamak [55]. BES observes long-wavelength $\left(k_{\perp}<3 \mathrm{~cm}^{-1}\right)$ density fluctuations associated with plasma turbulence that drives cross-field particle, energy, and momentum transport [56]. Density measurements are obtained by observing the Doppler-shifted fluorescence $(n=3-2)$ of a heating neutral beam as the neutrals undergo collisional excitation via interactions with plasma ions and electrons. Radially and poloidally localized $(\Delta R \approx \Delta Z \approx 1 \mathrm{~cm})$ measurements are obtained by aligning the optical sightline to the local magnetic field lines at the beam-sightline intersection.

A high-throughput lens $(\mathrm{f} / 2,40 \mathrm{~cm})$ images a section of the neutral beam onto a set of fiber optic bundles that relay the light to a remote location. A spectrometer consisting of a collimating and focusing lens and a high transmission interference filter selects the desired wavelength band $(652-655 \mathrm{~nm})$, integrating the $D_{\alpha}$ neutral beam emission while 
isolating the undesired recycling light emission. A high quantum efficiency photodiode measures the light signal, which is processed by cryogenically cooled ultra-low noise preamplifiers and sampled typically at $1 \mathrm{MHz}$. Broadband density fluctuations typically exist in the 5-400 kHz region. The DIII-D BES system consists of 32 spatial channels that can be deployed in many different spatial configurations and radially scanned remotely on a shot-to-shot basis.

A significant advance with the DIII-D BES system is the capability to directly image density fluctuations across the width of the beam path at modest spatial resolution by deploying the channels in a $2 \mathrm{D}$ configuration $(5 \times 6$ or $4 \times 8$ channels is a typical arrangement) [57]. An example sequence of images are shown in Fig. 7. Each image is obtained in one microsecond and is separated from the next by 8 microseconds.
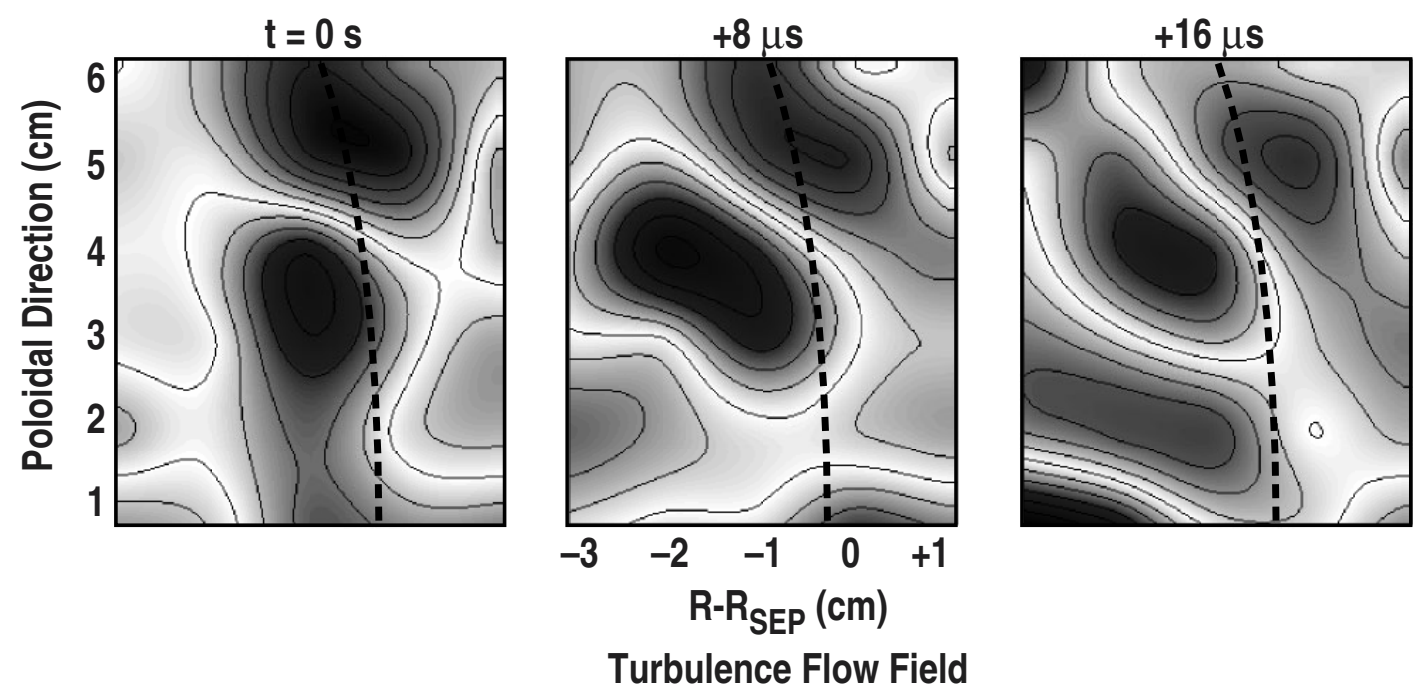

Turbulence Flow Field

Fig. 7. Three images of density fluctuations obtained with BES, with $8 \mu$ s separation in time. Images obtained from 2D spline fit to $5 \times 6$ channel array. The dotted line is the plasma separatrix.

\section{Microwave reflectometer}

The development and physics application of broadband, continuous frequency swept (FMCW) microwave reflectometer techniques for the measurement of electron density profiles has been extensively pursued on DIII-D. The system design philosophy and data analysis approach utilized in the DIII-D systems is based on radar analysis techniques [2,3], and has proved highly successful in providing reliable profile measurements. A Q-band (33-50 GHz) backward wave oscillator (BWO) source was replaced by a high performance, fast-sweep solid-state microwave source [58]. Expanding on previous X-mode measurements, O-mode core profile measurements were shown to be feasible and accurate [59], leading to the adoption of a variable polarization 
(O- or X-mode) antenna configuration [60,61]. The system is now capable of $10 \mu$ s time resolution, with a spatial resolution of $\pm 2 \mathrm{~mm}$ [61]. A new improved system is being installed with simultaneous $\mathrm{O}$ - and $\mathrm{X}$-mode measurements in both $\mathrm{V}$ - $(50-70 \mathrm{GHz})$ and Q-bands, which will expand the range of high performance density profile coverage to $0-6 \times 10^{19} \mathrm{~m}^{-3}$.

While developing the hardware and analysis capabilities of the DIII-D profile reflectometer system, direct physics application of the results has also been emphasized, for example, in studies of profile dynamics associated with fast plasma instabilities such as ELMs, the edge harmonic oscillation in QH-mode [62-64], and L-H transition physics, where changes in edge gradients provide a critical test of theory [65]. One example of such physics measurements is shown in Fig. 8, which illustrates time and spatially resolved measurements of edge density profile changes associated with ELMs.

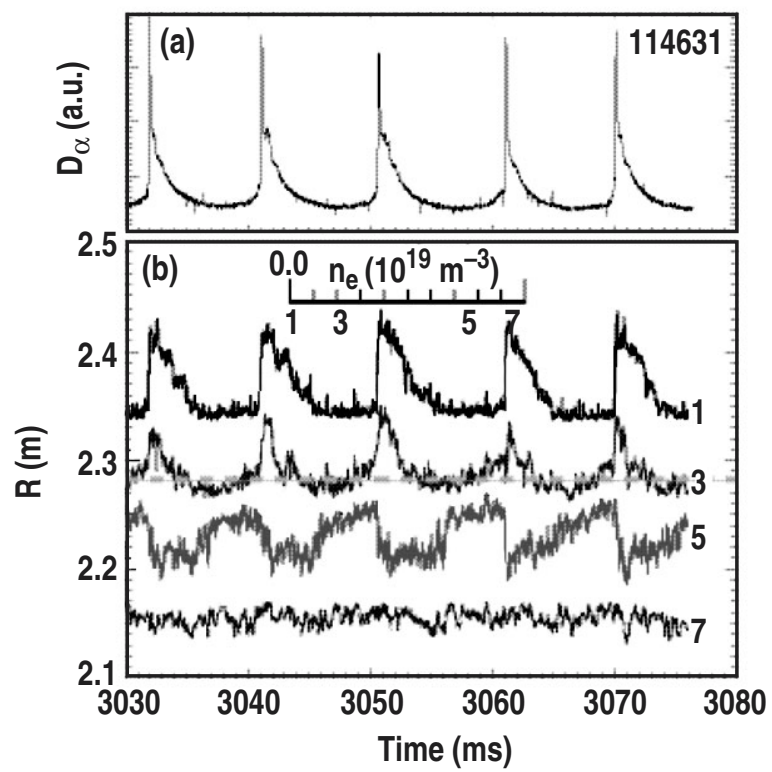

Fig. 8. Contour plot showing the variation in the edge density profile (b), across a series of ELMs (a), as determined from profile reflectometer measurements. An increase in density in the SOL and decrease inside the separatrix (horizontal dashed line) are clearly visible.

The radial correlation reflectometer system on DIII-D is a broadband frequency tunable system $(55-70 \mathrm{GHz})$ capable of accessing a large radial region on the midplane of the discharge [66]. This system determines the radial correlation function by fixing one of two probing frequencies and sweeping the other relative to it. Since frequency determines the radial position, a radial correlation function is then obtained by sweeping the frequency. Either O- or X-mode polarization can be used thus allowing a large range of densities to be accessed. The same launching and receiving horns are used for the two 
probing frequencies ensuring that they transit the same path within the plasma. The system uses a simplified tracking receiver circuit coupled with quadrature mixers which provide the ability to extract both phase and amplitude information from the plasma signal. Sweep periods are typically 50-100 ms which places a requirement on the plasma to remain stationary (in time). Radial profiles of the correlation length are built up on a discharge-by-discharge basis by varying the reflectometer probe frequency. An example of such a scan is shown in Fig. 9 which compares measured radial correlation lengths to various theoretical predictions.

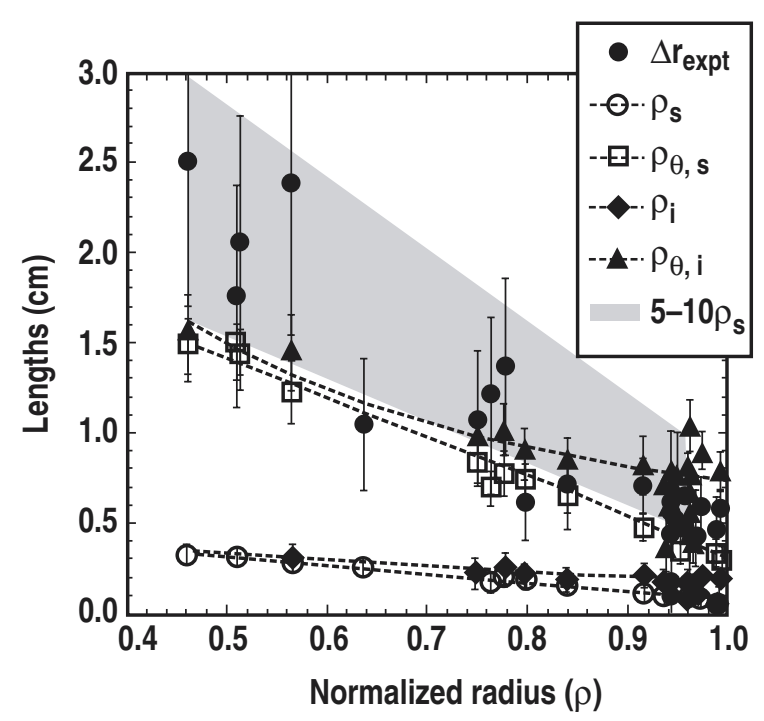

Fig. 9. Experimental values of correlation length $(\Delta r)$, ion gyroradius evaluated with the electron temperature $\left(\rho_{\mathrm{s}}\right)$, ion gyroradius $\left(\rho_{\mathrm{i}}\right)$, poloidal ion gyroradius $\left(\rho_{\theta, \mathrm{i}}\right)$, and poloidal ion gyroradius evaluated with the electron temperature $\left(\rho_{\theta, \mathrm{s}}\right)$ from the set of discharges. The shaded portion indicates 5-10 times $\rho_{\mathrm{s}}$. [Reprinted courtesy of AIP, Phys. Plasmas 9, 2141 (2002).]

The radial correlation reflectometer system can also be configured as a poloidal correlation reflectometer system. The same electronics and sources are used with the exception that separate antennas are used to receive the two launched frequencies. This allows poloidal phase velocities and correlation lengths to be estimated.

\section{J. Laser and microwave scattering}

A far infrared (FIR) collective scattering system for the study of density fluctuation behavior has been operational on DIII-D since the late 1980s [67,68]. Density fluctuations within the plasma scatter the probe radiation into an angle specified by the probe and fluctuation wave numbers, as detected by the system. The geometry of the system is such that the detected fluctuation signal is dominated by the poloidal features. Both broadband (turbulent) and narrowband (e.g. TAE modes) density fluctuations are 
observed. The probe beam is supplied by a backward wave oscillator with $\sim 300 \mathrm{~mW}$ of power at $288 \mathrm{GHz}$. The system is generally operated in a heterodyne configuration (it can be configured as a homodyne system) with local oscillator supplied by a passive tripler driven by a Gunn oscillator. The probe beam is directed along the plasma midplane and is reflected back upon itself from a specially designed carbon tile mirror located on the inside wall of the vessel. As the beam traverses the plasma (on its way back out) it is scattered by poloidally propagating density fluctuations into an angle which is determined by the wave numbers of the probe beam and of the density fluctuation. The choice of detection angle of the receiving optics then determines the wavenumber detected. A pair of wave number channels are acquired, typically 1 and $2 \mathrm{~cm}^{-1}$, or alternatively 2 and $5 \mathrm{~cm}^{-1}$.

On DIII-D it is often observed that the poloidal $E \times B$ velocity of the plasma dominates the intrinsic fluctuation frequency dispersion. Since the $E \times B$ velocity is radially varying, this results in the frequency spectra of the scattered data mapping onto radial position. That is, lower frequency fluctuations originate from regions of low $E \times B$ velocity, e.g. the edge of the plasma, while higher frequencies come from the core where the $E \times B$ velocity is larger. Since the system is heterodyne and the $E \times B$ velocity changes sign along the midplane, the fluctuation signals from the low and high field sides of the plasma have different signs of frequency and so can be differentiated in this way. This rough frequency to radial position mapping allows an improved interpretation of the largely chord averaged signal.

An interesting example of data from the FIR scattering system is shown in Fig. 10. Displayed are two sets of power spectra, one from a high density (labeled $n>2 \times 10^{13} \mathrm{~cm}^{-3}$ ) and one from a low density discharge (labeled $n<2 \times 10^{13} \mathrm{~cm}^{-3}$ ). In the lower density case (LOC) the global thermal confinement is observed to increase linearly with chord averaged density while the confinement saturates with density for the higher density case (SOC). The difference between the two spectra is shown in the inset.

\section{K. Phase contrast imaging (PCl)}

A PCI diagnostic has been operational on DIII-D for over ten years [69]. The measurement is made by passing a large diameter $\mathrm{CO}_{2}$ laser beam through the plasma and using the PCI technique to create an image on a linear detector array of the phase shift of the beam induced by the plasma. This phase shift is proportional to the plasma density, so the signal corresponds to radial variations in the fluctuating plasma density along the beam path [70]. 


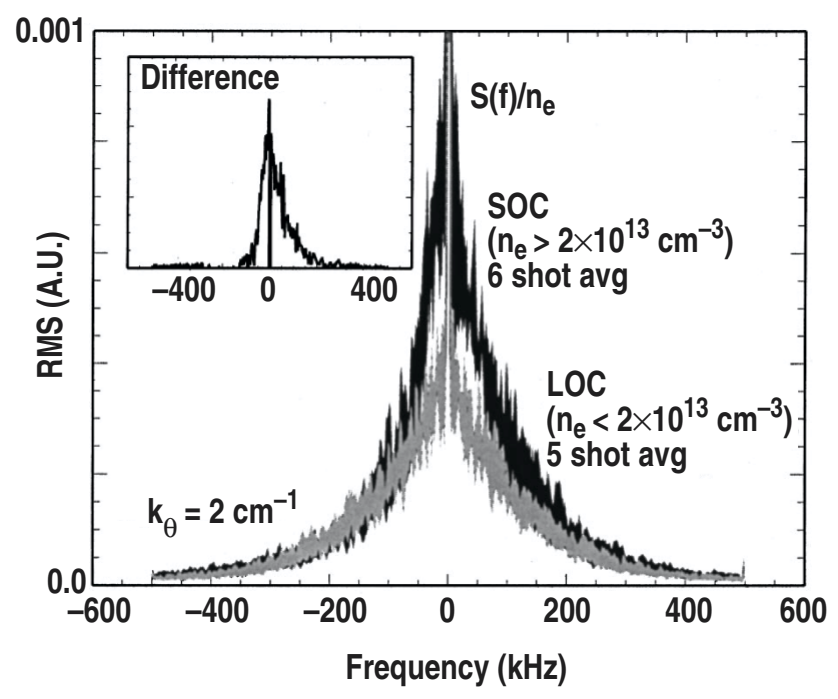

Fig. 10. Frequency dependence of the scattered radiation during low-density (LOC) discharges (gray) and high-density (SOC) discharges (black), respectively. Shown are the spectra averaged over multiple discharges normalized by the line average density, with shading to indicate the standard deviation over the set of discharges. In the inset, the difference is shown, indicating that the incremental fluctuations are concentrated over a lower frequency range than the baseline spectra. [Reprinted courtesy of AIP, Phys. Plasmas 8, 2232 (2001).]

Before the 2003 experimental campaign, the PCI laser beam passed vertically through the edge of the plasma at the outboard midplane near the last closed flux surface. In this geometry, the PCI signal includes components of the turbulence for which $k_{\theta}<0.1 k_{\mathrm{r}}$, where $k_{\theta}$ and $k_{\mathrm{r}}$ are the poloidal and radial wave vectors respectively with $k_{\mathrm{r}}$ between 1 and $10 \mathrm{~cm}^{-1}$, at frequencies between $8 \mathrm{kHz}$ and $1 \mathrm{MHz}$. The data is used to calculate quantities such as autopower spectra vs. radius or $k_{\mathrm{r}}$, and radial correlation lengths. Observed spectra are seen to peak at finite $k_{\mathrm{r}}$, a feature which is evidence of zonal flows [71]. The system is being modified to view the core of the plasma, with wave vectors as high as $50 \mathrm{~cm}^{-1}$. 


\section{DIAGNOSTICS RELATED TO STABILITY STUDIES}

The understanding and control of plasma stability has also been an early focus of fusion plasma studies. This field of study has grown from a basic set of magnetic loop and coils (e.g. magnetics) to sophisticated diagnostics based on plasma emission such as the motional Stark effect (MSE) and Zeeman polarimetry of a lithium beam, which are the basis for deriving the plasma current profile. Other techniques such as soft $\mathrm{x}$-ray imaging and disruption radiometers (DISRAD) are very helpful in reconstructing plasma internal structures while measurements of edge currents (tile current array) are used to reconstruct the plasma external structures. Many details of these techniques can be found in the following section.

\section{A. Magnetics}

The DIII-D magnetic diagnostics are a mature and reliable system that is essential to the daily operation of the tokamak. This system includes approximately 250 inductive sensors of various types: axisymmetric poloidal flux loops, toroidal (diamagnetic) flux loops, local magnetic field probes, and Rogowski loops for coil currents and plasma current. The primary uses of the data include post-discharge equilibrium reconstruction [72], real-time equilibrium reconstruction for plasma current, plasma shape and position control [73], spectrum analysis in time and space of MHD instabilities, and, most recently, for direct feedback control of slowly growing plasma instabilities. A prototype analog-digital integrator has been developed [74] to meet the challenge of using inductive magnetic sensors during very long pulses in future tokamaks.

The approximately 80 magnetic field probes are made of mineral insulated co-axial wound on a ceramic form, a design similar to that planned for ITER [4,75]. The design has proven highly reliable: there have been no failures of the components located in the primary vacuum, although many of the probes have been in service for more than 15 years. The DIII-D probes were designed to maximize both active coupling area and bandwidth in order to serve dual purposes of equilibrium and fluctuation measurements [76,77]. Their practical bandwidth is about $200 \mathrm{kHz}$, encompassing most of the frequency range of interest for MHD instabilities. This design allows these probes to be used for detection and control of various MHD instabilities that are likely to be encountered in 
burning plasma experiments. With magnetic probes as the control input, neoclassical tearing modes have been stabilized using feedback-controlled electron cyclotron current drive [78].

\section{B. Soft x-ray diode arrays}

The soft X-ray (SXR) diode arrays are used to measure fluctuations in the SXR emission and provide information on plasma instabilities. Two arrays, each with 32 detectors, provide nearly orthogonal views spanning the entire poloidal cross section of the torus at a single toroidal location (90 deg), and are used to investigate the poloidal structure of MHD activity, including sawtooth oscillations and activity associated with high beta discharges. Additional arrays of 12 detectors each are installed at three separate toroidal locations (45, 165 and $195 \mathrm{deg}$ ), and are primarily used for toroidal mode identification. The detectors are solid-state silicon diodes operated in the current mode, and measure the $\mathrm{x}$-ray emission from $\sim 2$ to $20 \mathrm{keV}$. The signal from each $\mathrm{x}$-ray channel is split into two components; a slow $(\sim 500 \mathrm{~Hz})$ component capable of digitizing the entire plasma discharge and a fast $(\sim 100 \mathrm{kHz})$ component $[79,80]$.

In addition to the usual studies of sawtooth activity and precursor oscillations, the SXR arrays on DIII-D have been used to study MHD activity during high beta plasma operation. Without feedback stabilization, the resistive wall mode (RWM) limits the performance of DIII-D discharges when the plasma beta exceeds the no-wall stability limit. The x-ray measurements, in combination with magnetic probe data, confirm the global kink structure of the RWM. The plasma displacements predicted by MHD stability codes are mainly poloidal but with net radial components. The toroidally separated soft $\mathrm{x}$-ray arrays can observe the non-axisymmetric radial displacements. Chord-by-chord comparisons of the $\mathrm{x}$-ray data are used to find the relative radial displacements between two toroidal locations at minor radii corresponding to the x-ray sight lines.

\section{Current density measurements}

The poloidal magnetic field and the associated current density profiles are measured using two diagnostics. The first one is based on the MSE technique. This system consists of 44 channels distributed along three views $[81,82]$. The combination of these three views also allows the measurement of the radial electric field [82]. In addition, a second diagnostic, based on the Zeeman polarimetry of a $30 \mathrm{keV}$ injected lithium beam, allows the detailed measurements of the poloidal field pitch (and current density) near the edge of the plasma [83]. The lithium beam diagnostic is shown schematically in Fig. 11. 
Additional details and a discussion of the results can be found in a separate paper within this issue.

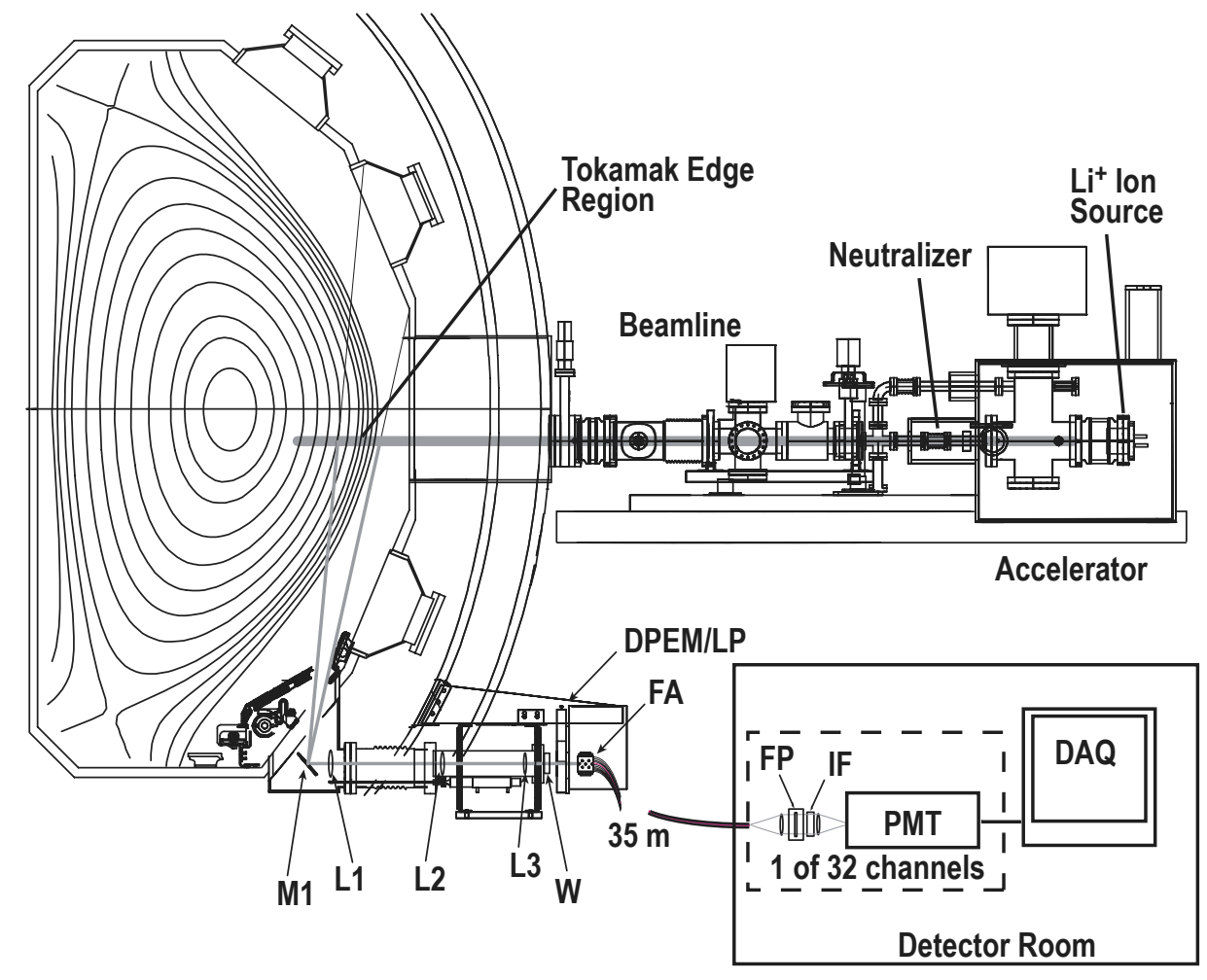

Fig. 11. Neutral lithium beam system and viewing optics system on DIII-D for the Zeeman polarization diagnostic. Beam parameters: $30 \mathrm{keV}, 10 \mathrm{~mA}, 1-2 \mathrm{~cm}$ diameter. Radial resolution $5 \mathrm{~mm}$. Lenses L1, L2, L3 and window, W, are SFL6 (low Verdet constant) glass and the polarization-maintaining mirror M1, has a special coating compatible with extended vacuum exposure and high $\left(350^{\circ} \mathrm{C}\right)$ temperature. Dual photo-elastic modulator (PEM) fundamental frequencies are 23 and $20 \mathrm{kHz}$. Fiber array (FA) allows up to 32 radial channels to be observed simultaneously.

\section{Tile current monitors}

DIII-D is built with a continuous, all-metal vacuum vessel. The vessel is covered by graphite armor tiles, which comprise most of the plasma-facing surface. Characteristic plasma-facing tile dimensions are $\sim 0.15 \mathrm{~m}$ on an edge. The tiles receive and conduct electric current from the plasma with useful spatial resolution in the toroidal and poloidal directions. In order to study the large vessel currents and forces that appear during vertical instability of diverted plasmas a tile current array (TCA) containing three tile current monitors (TCMs) was installed [84], each monitor consisting of a compensated Rogowski loop wrapped around the base of a selected divertor target tile. A set of six, more-sensitive TCMs was installed poloidally across the lower divertor target in 1990 [85]. These and all subsequent DIII-D TCMs have each of the instrumented tiles 
electrically insulated from the vessel, and the tile current is conducted via a thin metal sheet electrode in pressure contact under the tile base to a sensing resistor, whose far end is securely bolted to the vessel wall. A $15 \mathrm{kHz}$ optical isolator in each signal channel breaks the ground loops formed by connecting the sensing resistors to the vessel. TCMs were also installed on the DIII-D centerpost, in the upper divertor, and at multiple toroidal locations. Most recently, thirty TCM signals are branched to faster optical isolators connected to digitizers that usually run at $200 \mathrm{ksample} / \mathrm{s}$. The fast channels were built by Princeton Plasma Physics Laboratory, and they are called "Halo Current Diagnostic" (HCD) channels to distinguish them from the slower original channels. Measurements using the tile current array were also used to benchmark analytic models of toroidally symmetric disruption currents, forces, and their scalings [84,86-89].

Presently, tile current research at DIII-D is using the high-speed HCD system to explore SOL current phenomena associated with plasma instabilities [84,86,90,91]. The distribution of ELM currents is found to be very non-uniform toroidally and extremely non-uniform in time. The TCA is also helping to characterize and understand the physics of stochastic magnetic boundaries in diverted plasmas [92].

\section{E. Disruption radiometer (DISRAD)}

The disruption radiometer "DISRAD-II" [93] measures radiated power from the plasma with 30 -chord spatial resolution and up to $1 \mathrm{MHz}$ bandwidth. The thirty chords fan out from a single port across a poloidal slice of the plasma. The diagnostic employs silicon "Absolute eXtreme Ultra-Violet (AXUV)" photodiodes, which are sensitive across the entire radiation spectrum from the visible up to several-keV soft $\mathrm{x}$-rays. DISRAD has proved useful in ELM characterization studies as well as in disruption experiments. Its development was motivated originally by a need for diagnostics for disruption studies that were fast enough to time resolve these events and also provided measurements that were valid under the relevant plasma conditions. DISRAD is a key diagnostic in the understanding of the effect of high-pressure gas jets in disruption mitigation experiments in DIII-D. It has also contributed to studies of the propagation of Type-I ELMs, as these events produce substantial radiation in the boundary plasma. 


\section{DIAGNOSTICS RELATED TO BOUNDARY STUDIES}

The interaction of hot fusion plasmas with confining structures (such as found in a tokamak) requires many specialized diagnostics. This set includes fundamental monitors of impurity radiation and impurity density (filterscopes, multi-chordal spectrometers, pressure gauges, viewing cameras of various speeds and locations). The overall impact of impurity radiation is also diagnosed using a large set of bolometers located at the periphery. At the same time the effects of plasma interaction with the surrounding walls is characterized by infrared cameras and probes, fixed (e.g. Langmuir) and scanning. Their role is further described in this section.

\section{A. Spectral line monitors ("filterscopes")}

DIII-D is equipped with spectral line monitors which provide column-integrated measurements of deuterium and impurity line emission along twenty-four different spatial view chords in the upper and lower divertors, and at the outboard midplane [94]. Compact, multi-channel detector modules incorporating dielectric spectral filters with $1 \mathrm{~nm}$ or $2 \mathrm{~nm}$ bandpass and miniature Hamamatsu photomultipliers tubes with built-in high voltage power supplies, permit simultaneous recording of $D_{\alpha}, D_{\beta}, \mathrm{C}$ III, He II signals along each viewing chord on every discharge with sampling rates up to $100 \mathrm{kHz}$. The high time resolution has been used to study edge localized modes (ELMs) and to obtain snapshots of turbulence in the scrape-off layer (SOL) [95]. $\mathrm{D}_{\alpha}$ data from the array of eight tangential viewchords on the outer midplane have been inverted, yielding neutral densities and ionization rate profiles in the plasma edge and SOL [96].

\section{B. Fast, neutral pressure gauges (“ASDEX gauges”)}

Six fast, neutral pressure gauges, located at key positions in the upper and lower divertors and at the vessel midplane, monitor the evolution of neutral pressure during a discharge resulting from plasma particle recycling on divertor targets and other wall surfaces. These gauges are commercial variants of an rf-modulated, ionization gauge developed at IPP in Garching [97]. Combined with knowledge of the effective pumping speeds of the cryogenic pump rings in the divertor plenums, these pressure measurements yield the particle exhaust efficiency from each of the divertor legs for the various configurations (lower single-null, upper single-null, double-null, and inner wall-limited) run in DIII-D. The effect of various conditioning methods on particle control, a key 
requirement for achievement of the high confinement "H-mode" regime on DIII-D and other tokamaks, was advanced by exhaust studies in DIII-D [98]. The role of magnetic balance in the plasma loading at the inner and outer divertor targets has also relied heavily on information from the neutral pressure gauges and $D_{\alpha}$ line monitors [99].

\section{High resolution, multichordal divertor spectrometer}

In the divertor of DIII-D, spectroscopy of deuterium, low-Z impurity elements, and hydrocarbon fragments has been carried out with a high resolution $(0.015 \mathrm{~nm})$ multi-chordal visible spectrometer equipped with a CCD camera. Diagnosis of ion temperature, parallel plasma flows, and impurity fluxes have utilized near vertical views into the upper and lower divertors along with tangential views of the lower divertor [100]. Long monofilamentary quartz fibers couple the light collection optics at the tokamak to the spectrometer and detector which are located outside the radiation shield wall of the torus hall. Analysis of temperature and flow velocities from line profiles with nonlinear splitting of magnetic sublevels relies on the least squares fitting of the measured line profiles to ab-initio calculations of the theoretical line shapes. The magnitude and direction of the total magnetic field, derived from an equilibrium code (EFIT) solution, is input to the code for the calculation of theoretical profile along each segment of a viewchord [101].

\section{Tangentially viewing camera systems}

The tangentially viewing camera systems on DIII-D provide information on the spatial distribution of radiation sources in the main chamber SOL and divertor regions for a large variety of modes of operation in the boundary plasma. Three systems are used extensively: 1) a set of two cameras each looking at line-filtered visible emission from the lower and upper divertors respectively [102], 2) a camera in each of the divertors that images the VUV emission at $155 \mathrm{~nm}$ from the $\mathrm{C}^{3+}$ ion [103], and 3) a line-filtered visible emission view of the inner and outer SOLs at the main chamber midplane [104]. Line-filtered emission from these cameras complements the measurement of total radiated power from the bolometer systems by providing data on the spatial profile of individual radiating species in the boundary plasma.

Through a series of experiments, it was found that detachment of the DIII-D divertors required a local, highly radiating zone to form in the SOL near the X-point [105]. For most detachment scenarios with deuterium puffing, this emission accounted for more than half of the radiated power measured in the divertor by the bolometers. Comparison of the emission profiles from the CIV VUV system with emission from 
visible CIII at $456 \mathrm{~nm}$ showed that a diagnostic of the visible CIII emission, which is far easier to implement on future devices than a VUV measurement, gives an accurate spatial profile of the zone of high radiated power from carbon. In experiments that achieved divertor detachment with injection of non-intrinsic impurities (neon and argon in DIII-D), the cameras combined with outer spectrometer measurements showed that carbon radiation contributed a larger fraction of the total radiated power in the divertor than the injected impurities. Combining the emission profiles from the divertor and main chamber cameras shows that the dominant source of deuterium neutrals and carbon impurities is from the divertor regions. All of these measurements contributed to the detailed understanding of divertor detachment that forms the basis for the ITER baseline operating scenario with detached divertors and closed, baffled divertor geometry [105].

One of the lower divertor visible views and the main chamber midplane view use fast gated, intensified cameras. The gated systems provide snapshots every $17 \mathrm{~ms}$ of the emission with short (as little as $10 \mu \mathrm{s}$ ) integration time. The evolution of $D_{\alpha}$ and CIII visible emission in the divertor during ELMs [106] showed that the hydrogenic emission profile changes very little during ELMs although the intensity increases substantially.

\section{E. Bolometers}

The bolometer arrays on DIII-D were designed to optimize measurement of the 2D profile of divertor radiation while still providing good coverage for the core plasma [109]. The detectors consist of a platinum foil resistor whose resistance increases with absorption of plasma radiation. The measurement electronics are based on a TFTR design [110]. The detectors are arranged into two arrays separated poloidally by approximately 90 degrees. The core plasma radiation is fit to a 1-D spline function while the radiation profile in the divertor region is fitted to using a smoothed least squares approximation based upon the magnetic equilibrium [111]. The combination of good spatial resolution, 2-D analysis, and flexible magnetic geometry allowed the first measurements of radiation distributed along the divertor leg during target plate heat flux reduction experiments (Fig. 12) [112].

\section{F. Infra-red TV system (IRTV)}

The IRTV system for DIII-D uses infrared camera views of the upper and lower divertors, upper and lower inner wall, and under the lip of the lower cryopump, to measure surface temperature of the first wall graphite tiles. The cameras view through germanium lenses and $\mathrm{ZnSe}$ vacuum windows. Some cameras have had fast-scanning profile measurement capability useful for study of ELMs and disruptions. Time-resolved 
temperature profile measurements and knowledge of the thermal properties of the material allow computation of heat flux as a function of time and position on the surface. This is useful in demonstrating the reduction of divertor heat flux by means of a radiative divertor (Fig. 12) [107,108].

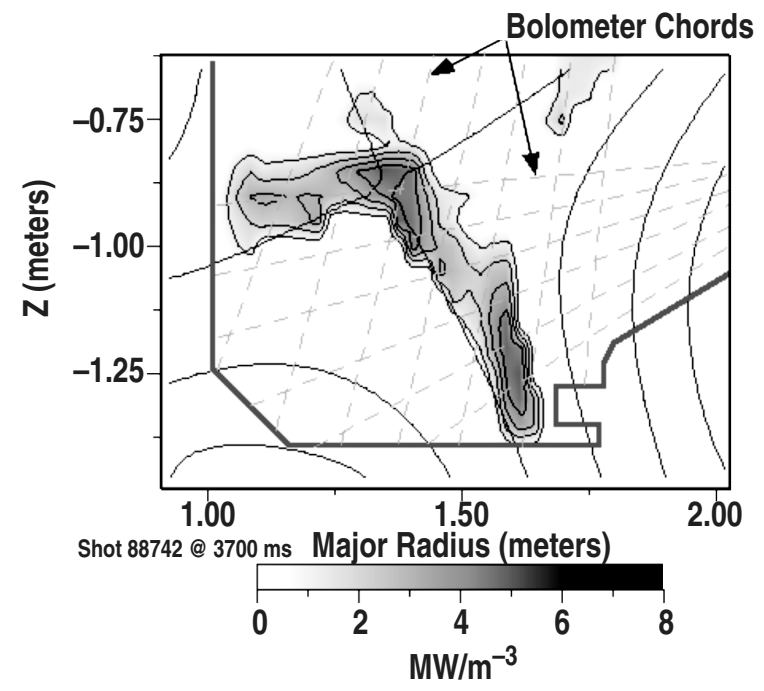

Fig. 12. The radiation profile for radiative divertor operation in DIII-D. The variation in radiation from the $\mathrm{X}$-point to the divertor target is no more than a factor of 2 within the spatial resolution of the bolometer array, whose chords are also shown.

Various data acquisition schemes have been used including videotape recording and post-processing using video frame-grabbers. Presently we use cameras with internal digitizers whose output is captured digitally. The full video stream is stored in a database. Cameras are calibrated during baking of the vacuum vessel by recording camera signals and tile temperatures from thermocouples embedded in graphite tiles. The capture of calibration data is automated except for startup procedures.

\section{G. Divertor Materials Evaluation System (DiMES)}

The DiMES uses a sample changer mechanism to expose different ITER relevant materials to the lower divertor of DIII-D to study integrated plasma materials interaction effects in a tokamak and to benchmark modeling codes. Material sample can be exposed to the plasma for as little as one plasma discharge. With its ease of sample change out, the DiMES system is also providing support in the development of advanced diagnostics. For example, a tile calorimeter diagnostic has been tested on the DiMES system in order to measure the heat flux to the divertor plate. This instrument gives an independent measurement of the heat flux to complement IR measurements, which can suffer from uncertainties in the emissivity of the divertor plates [113]. 


\section{H. Reciprocating probes}

A wealth of information on boundary plasma profiles, fluctuations, turbulence, and turbulent cross-field transport are provided for DIII-D by a pair of fast reciprocating Langmuir probe arrays, one located on the low field side of the plasma near the midplane with a horizontal motion (the "midplane probe" [114]), and one located in the lower divertor with a vertical motion (the "X-point probe" [115]). Both probe arrays consist of five tips which are scanned pneumatically over $10 \mathrm{~cm}$ radially from the vessel wall (midplane) or $15.25 \mathrm{~cm}$ vertically from the divertor floor (X-point probe) at speeds of $3 \mathrm{~m} / \mathrm{s}$. The probe systems provide high bandwidth data (up to $2.5 \mathrm{MHz}$, limited by digitizer sampling rates) with high spatial resolution at up to three distinct times in a given discharge. Although the configuration of the probe systems has varied over time, these systems currently provide time-averaged profiles of ion saturation current $I_{\text {sat }}$, electron density $n_{\mathrm{e}}$, electron temperature $T_{\mathrm{e}}$, floating potential $\phi_{\mathrm{f}}$, and for the X-point probe, plasma flows parallel to B (Mach probe). From these data, is it possible to estimate profiles of the plasma potential $\phi_{\mathrm{p}}$ and its derivatives (e.g. radial electric field $E_{\mathrm{r}}$, and the poloidal electric field $E_{\theta}$ ). In addition, the probes provide broadband ( $\mathrm{dc} \leq f \leq 2.5 \mathrm{MHz}$ measurements of $I_{\mathrm{sat}}, T_{\mathrm{e}}$, and $\phi_{\mathrm{f}}$ fluctuations with 80-100 db of dynamic range. These data are then used to estimate the turbulent particle flux $\Gamma_{\mathrm{r}}$ and turbulent convective and conductive heat fluxes $Q_{\text {conv }}$ and $Q_{\text {cond }}$.

Midplane probe measurements were among the first to show evidence for increases in $E_{\mathrm{r}}$ in the L-mode prior to the L-H transition [25,116]. By scanning the maximum insertion radius of the probe on successive identical discharges and measuring at the $\mathrm{L}-\mathrm{H}$ transition, the probe data showed a clear change in $\phi_{\mathrm{f}}$ in the plasma edge, the radial electric field increased over a $4 \mathrm{~ms}$ period, which followed a fast ( $<50 \mu \mathrm{s})$ suppression of the fluctuation amplitude and transport. The DIII-D midplane probe also provided the first direct measurement of a reduction in turbulent transport (as opposed to fluctuation amplitudes) at the L-H transition [25,116], and discovered the important role played by changes in the $n-\phi$ cross-phase in the transport suppression [116-118].

\section{Fixed divertor Langmuir probes}

The DIII-D target plate Langmuir probe system currently consists of 54 domed graphite probe tips (6 $\mathrm{mm}$ diameter) mounted in the upper and lower divertor target plates. The probes are distributed approximately $3 \mathrm{~cm}$ apart in the lower divertor and $1.25 \mathrm{~cm}$ apart near the upper divertor strike points and further apart in between the strike points. By sweeping the voltage on the probe tips, the probes can be used to measure the local parallel particle flux, electron temperature, electron density, and floating potential at 
sampling rates up to $100 \mathrm{kHz}$. The probes extend $1 \mathrm{~mm}$ above the tile surface to give a well-defined area. Presently 24 probes can be operated simultaneously. The tips need to be replaced at least every other year to ensure the shape is as expected after exposure to the plasma [119]. 


\section{SUMMARY}

An extensive set of diagnostics has enabled detailed physics studies on the DIII-D tokamak over the last 20 years. This collection of instruments results from a long and fruitful collaboration with many groups from various institutions both from within the United States and abroad. These scientific discoveries cover four

major topical science areas (transport, stability, heating and current drive, and boundary science), focusing on one major thrust based on the development of the Advanced Tokamak regime.

While extensive, a few significant gaps remain on the diagnostic coverage of fusion plasmas as found in a tokamak. One area of particular interest for DIII-D, and elsewhere, is the diagnosis of the fast ion population (both in space and time) produced by neutral beams or $\mathrm{rf}$ injection. This is especially important for the evaluation of the plasma stability, and in return, of the effects of instabilities on the fast ion distribution itself. This area of research is critical for the success of the DIII-D mission and bears directly on the future performance of ITER and other experiments.

One other critical area of research is to study the migration (sputtering and deposition) of impurities throughout the plasma discharge and especially in the boundary area, including the divertor. However, in order to diagnose these effects, measurement of plasma flows appears to be critical for our physical understanding of particle transport. The needs for 2D measurements and spatial localization of these flows are severe constraints on this diagnostic development and satisfactory solutions are still elusive, although the subject of intense research.

Finally, in the area of transport, one key measurement that would enable a fundamental understanding of plasma dynamics relate to the direct diagnosis of plasma flux. Right now, very limited information is obtainable in regards to particle, momentum and heat flux. Largely believed to be driven by turbulence these fluxes hold the key to the understanding in how these fusion plasmas behave, and how to control them. 


\section{REFERENCES}

[1] K. Ebisawa, A.E. Costley, A.J.H. Donne, G. Janeschitz, S. Kasai, et al., Rev. Sci. Instrum. 72, 545 (2001).

[2] E.J. Doyle, et al., "Reflectometry Applications to ITER," in Diagnostics for Experimental Thermonuclear Fusion Reactors, Ed. P.E. Stott, G. Gorini and E. Sindoni (Plenum Press, New York, 1996) p. 117.

[3] E.J. Doyle, et al., "Design Basis for the ITER Plasma Shape and Position Control Reflectometer System," in Diagnostics for Experimental Thermonuclear Fusion Reactors 2, Ed. P.E. Stott, G. Gorini, and E. Sindoni (Plenum Press, New York, 1998) p. 119.

[4] ITER Physics Expert Group on Diagnostics (K.M. Young, et al.) Nucl. Fusion 39, 2541 (1999).

[5] R.C. Isler, Phys. Rev. Lett. 30, 1359 (1977).

[6] R.J. Fonck, et al., Appl. Phys. Lett. 42, 239 (1983).

[7] R.J. Groebner, et al., Appl. Phys. Lett. 43, 920 (1983).

[8] R.J. Fonck, D.S. Darrow, and K.P. Jaehnig, Phys. Rev. A 29, 3288 (1984).

[9] R.P. Seraydarian, K.H. Burrell, N.H. Brooks, R.J. Groebner, and C. Kahn, Rev. Sci. Instrum. 57, 155 (1986).

[10] R.P. Seraydarian and K.H. Burrell, Rev. Sci. Instrum. 57, 2012 (1986).

[11] R.P. Seraydarian, K.H. Burrell, and R.J. Groebner, Rev. Sci. Instrum. 59, 1530 (1988).

[12] K. Ida and S. Hidekuma, Rev. Sci. Instrum 60, 867 (1989).

[13] A. Boileau, M. Von Hellermann, L.D. Horton, J. Spence and H.P. Summers, Plasma Phys. Control. Fusion 31, 779 (1989).

[14] R.J. Groebner, K.H. Burrell, and R.P. Seraydarian, Phys. Rev. Lett. 64, 3015 (1990).

[15] R.J. Groebner, K.H. Burrell, P. Gohil, and R.P. Seraydarian, Rev. Sci. Instrum. 61, 2920 (1990).

[16] P. Gohil, K.H. Burrell, R.J. Groebner, and R.P. Seraydarian, Rev. Sci. Instrum. 61, 2949 (1990).

[17] M. von Hellermann, W. Mandl, H.P. Summers, H. Weisen, A. Boileau, et al., Rev. Sci. Instrum. 61, 3479 (1990). 
[18] K. Ida, H. Yamada, H. Iguchi, K. Itoh, and CHS Group, Phys. Rev. Lett. 67, 58 (1991).

[19] P. Gohil, et al., in Proceedings of the Fourteenth IEEE/NPSS Symposium on Fusion Technology, Vol II (IEEE, Princeton, 1992) p. 1199.

[20] R.C. Isler, Plasma Phys. Control. Fusion 36, 171 (1994).

[21] Y. Koide, et al., Phys. Rev. Lett. 72, 3663 (1994).

[22] R.E. Bell, L.E. Dudek, B. Grek, D.W. Johnson, and R.W. Palladino, Rev. Sci. Instrum. 70, 821 (1999).

[23] K.H. Burrell, E.J. Doyle, P. Gohil, R.J. Groebner, J. Kim, et al., Phys. Plasmas 1, 1536 (1994).

[24] K.H. Burrell, et al., in Plasma Physics and Controlled Nuclear Fusion Research 1994, Vol. 1 (IAEA, Vienna, 1995) p. 221.

[25] R.A. Moyer, K.H. Burrell, T.N. Carlstrom, S. Coda, R.W. Conn, et al., Phys. Plasmas 2, 2397 (1995).

[26] R.J. Groebner, et al., in Proceedings of the Sixteenth European Conference on Controlled Fusion and Plasma Physics, Venice, 1989, Vol. 13B (EPS, PetitLancy, Switzerland, 1989) p. 245.

[27] K.H. Burrell, Phys. Plasmas 4, 1499 (1997).

[28] K.H. Burrell, Phys. Plasmas 6, 4418 (1999).

[29] P.W. Terry, Rev. Mod. Phys. Rev. Mod. Phys. 72, 109 (2000).

[30] D.K. Finkenthal, PhD Thesis, University of California Berkeley (1994).

[31] M.R. Wade, D. Finkenthal, D.L. Hillis, C. Klepper, W.P. West, et al., Rev. Sci. Instrum 63, 5170 (1992).

[32] M.R. Wade, D.L. Hillis, J.T. Hogan, M.A. Mahdavi, R. Maingi, et al., Phys. Rev. Lett 74, 2702 (1995).

[33] M.R. Wade, D.L. Hillis, J.T. Hogan, R. Maingi, M.M. Menon, et al., Phys. Plasmas 2, 2357 (1995).

[34] P. Gohil, K.H. Burrell, R.J. Groebner, K. Holtrop, D.H. Kaplan, and P. MonierGarbet, Rev. Sci. Instrum. 70, 878 (1999).

[35] K.H. Burrell, et al., Plasma Phys. Control Fusion 46 (to be published).

[36] R.J. Fonck, et al., Appl. Optics 21, 2115 (1982).

[37] J.S. Haskovec, et al., "FOMA - A Fast Optical Multichannel Analyzer," in Proceedings of the Thirteenth Symposium on Fusion Engineering, Oak Ridge, Tennessee, 1989 (IEEE, 1989).

[38] K. Kadota, et al., Nucl. Fusion 20, 209 (1980).

[39] D.P. Schissel, et al., Phys. Fluids 31, 3738 (1988). 
[40] C.M. Greenfield, G.L. Campbell, T.N. Carlstrom, J.C. DeBoo, C.-L. Hsieh, et al., Rev. Sci Instrum. 61, 3286 (1990).

[41] P.K. Trost, T.N. Carlstrom, J.C. DeBoo, C.M. Greenfield, C.L. Hsieh, and R.T. Snider, Rev. Sci. Instrum. 61, 2864 (1990).

[42] T.N. Carlstrom, J.C. DeBoo, R. Evanko, C.M. Greenfield, C.-L. Hsieh, et al., Rev. Sci Instrum. 61, 2858 (1990).

[43] C.L. Hsieh, J. Haskovec, T.N. Carlstrom, J., C.M. Greenfield, et al., Rev. Sci Instrum. 61, 2855 (1990).

[44] T.N. Carlstrom, G.L. Campbell, J.C. DeBoo, R. Evanko, J. Evans, et al., Rev. Sci Instrum. 63, 4901 (1992).

[45] T.N. Carlstrom, C.-L. Hsieh, R.E. Stockdale, D.G. Nilson, and D.N. Hill, Rev. Sci Instrum. 68, 1195 (1997).

[46] S.L. Allen, et al., J. Nucl. Mater. 241-243, 595 (1997).

[47] D.R. Baker and S.T. Lee, Rev. Sci. Instrum. 49, 919 (1978).

[48] D.R. Baker, Rev. Sci. Instrum. 51, 1304 (1980).

[49] E.S. Fairbanks, Rev. Sci. Instrum. 56, 905 (1985).

[50] T.N. Carlstrom, D.R. Ahlgren, and J. Crosbie, Rev. Sci. Instrum. 59, 1063 (1988)

[51] M.E. Austin, R.F. Ellis, J.L. Doane, and R.A. James, Rev. Sci. Instrum. 68, 480 (1997).

[52] M.E. Austin, J. Lohr, Rev. Sci. Instrum. 74, 1457 (2003).

[53] H. Ikezi, J.S. deGrassie, R.I. Pinsker, and R.T. Snider, Rev. Sci. Instrum. 68, 478 (1997).

[54] G.W. Watson, Thesis, University of California, Irvine (2003).

[55] G.R. McKee, R. Ashley, R. Durst, R. Fonck, M. Jakubowski, et al., Rev. Sci. Instrum. 70, 913 (1999).

[56] R.D. Durst, R. J. Fonck, G. Cosby, H. Evensen, and S.F. Paul, Rev. Sci. Instrum. 63, 4907 (1992).

[57] G.R. McKee, Rev. Sci. Instrum. 74, 2014 (2003).

[58] K.W. Kim, E.J. Doyle, T.L. Rhodes, W.A. Peebles, C.L. Rettig, and N.C. Luhmann, Jr., Rev. Sci. Instrum. 68, 466 (1997).

[59] E.J. Doyle, T.L. Rhodes, W.A. Peebles, and L. Zeng, Rev. Sci. Instrum. 70, 1064 (1999).

[60] L. Zeng, E.J. Doyle, T.C. Luce, and W.A. Peebles, Rev. Sci. Instrum. 72, 320 (2001).

[61] G. Wang, L. Zeng, E.J. Doyle, T.L. Rhodes, and W.A. Peebles, Rev. Sci. Instrum. 74, 1525 (2003). 
[62] L. Zeng, E.J. Doyle, T.L. Rhodes, G. Wang, W.A. Peebles, and K.H. Burrell, Rev. Sci. Instrum. 74, 1530 (2003).

[63] L. Zeng, et al., Plasma Phys. Control. Fusion, in press (2004).

[64] A.W. Leonard, T.H. Osborne, M.E. Fenstermacher, R.J. Groebner, et al., Phys. Plasmas 10, 1765 (2003).

[65] G. Wang, et al., Plasma Phys. Control. Fusion, in press (2004).

[66] T.L. Rhodes, W.A. Peebles, and E.J. Doyle, Rev. Sci. Instrum. 63, 4661 (1992).

[67] R. Philapona, E.J. Doyle, N.C. Luhmann, Jr., W.A. Peebles, C.L. Rettig, et al., Rev Sci Instrum 613007 (1990).

[68] C.L. Rettig, S. Burns, R. Philipona, W.A. Peebles, and N.C. Luhmann, Jr., Rev Sci Instrum 613010 (1990).

[69] S. Coda and M. Porkolab, Rev. Sci. Instrum. 66, 454 (1995).

[70] H. Weisen, Rev. Sci. Instrum. 59, 1554 (1988).

[71] S. Coda, M. Porkolab, and K.H. Burrell, Phys. Rev. Lett. 86, 4835 (2001).

[72] L.L. Lao, et al., Nucl. Fusion 30, 1035 (1990).

[73] J.R. Ferron, M.L. Walker, L.L. Lao, H.E. St. John, D.A. Humphreys, and J.A. Leuer, Nucl. Fusion 38, 1055 (1998).

[74] E.J. Strait, J.D. Broesch, R.T. Snider, and M.L. Walker, Rev. Sci. Instrum. 68, 381 (1997).

[75] L.C.J.M. de Kock and Yu.K. Kuznetsov, Nucl. Fusion 36, 387 (1996).

[76] E.J. Strait, Rev. Sci. Instrum. 67, 2583 (1996).

[77] A.S. Bozek and E.J. Strait, "Manufacturing of Magnetic Probe Coils for DIII-D," Proc. of the 21st IEEE Symposium on Fusion Engineering, San Diego, California, 2003 (Institute of Electrical and Electronics Engineers, Inc., Piscataway, New Jersey) to be published.

[78] R.J. La Haye, S. Günter, D.A. Humphreys, J. Lohr, T.C. Luce, et al., Phys. Plasmas 9, 2051 (2002).

[79] R.T. Snider, Rev. Sci. Instrum 66, 546 (1995).

[80] R.T. Snider, R. Evanko, and J. Haskovec, Rev. Sci. Instrum 59, 1807 (1988).

[81] B.W. Rice, Fusion Eng. and Design 34-35, 135 (1997).

[82] B.W. Rice, D.G. Nilson, K.H. Burrell, and L.L. Lao, Rev. Sci. Instrum. 70, 815 (1999).

[83] D.M. Thomas, Rev. Sci. Instrum. 74, 1541 (2003).

[84] E.J. Strait, et al., Nucl. Fusion 31, 527 (1991).

[85] M.J. Schaffer, B.J. Leikind, Nucl. Fusion 31, 1750 (1991).

[86] D.A. Humphreys, A.G. Kellman, Phys. Plasmas 6, 2742 (1999). 
[87] T.H. Jensen, D.G. Skinner, Phys. Fluids B 2, 2358 (1990).

[88] R.R. Khairutdinov, V.E. Lukash, Plasma Phys. Reports 22, 91 (1996).

[89] T.E. Evans, A.G. Kellman, D.A. Humphreys, M.J. Schafer, P.L. Taylor, et al., J. Nucl. Mater. 241-243, 606 (1997).

[90] T.E. Evans, et al., J. Nucl. Mater. 220-222, 235 (1995).

[91] M.J. Schaffer, et al., Proc. of 18th Conf. on Controlled Fusion and Plasma Phys., Berlin, 1991, Vol. 15C, Part III (EPS, 1991) p. 241.

[92] T.E. Evans, R.A. Moyer, P.R. Thomas, J.G. Watkins, T.H. Osborne, et al., "Suppression of Large Edge Localized Modes in High Confinement DIII-D Plasmas With a Stochastic Magnetic Boundary," submitted to Phys. Rev. Lett. (2004).

[93] D.S. Gray, E.M. Hollmann, S.C. Luckhardt, J. Chalfant, L. Chousal, et al., submitted to Rev. Sci. Instrum. (2004).

[94] R.J. Colchin, D.L. Hillis, C. Klepper, R. Maingi, and N.H. Brooks, Rev. Sci. Instrum. 74, 2068 (2003).

[95] R.J. Colchin, B.A. Carreras, R. Maingi, L.R. Baylor, T.C. Jernigan, et al., Nucl. Fusion 42, 1134 (2002).

[96] R.J. Colchin, et al., in Proc. of 20th Euro. Conf. on Control. Fusion and Plasma Phys., Budapest, 2000, ECA 24B (EPS, 2000) p. 760.

[97] G. Haas, et al., J. Nucl. Mater. 121, 151 (1984).

[98] R.J. Colchin, et al., J. Nucl. Mater. 472, 266 (1999).

[99] T.W. Petrie, J.G. Watkins, S.L. Allen, N.H. Brooks, M.E. Fenstermacher, et al., in Proc. of the 30th Euro. Conf. on Control. Fusion and Plasma Phys., St Petersburg, Russia (2003).

[100] R.C. Isler, N.H. Brooks, W.P. West, A.W. Leonard, G.R. McKee, and G.D. Porter, J. Nucl. Mater. 266-269, 376 (1999).

[101] R.C. Isler, et al., Phys. Plasmas 8, 4470 (2001).

[102] M.E. Fenstermacher, W.H. Meyer, R.D. Wood, D.G. Nilson, R. Ellis, and N.H. Brooks, Rev. Sci. Instrum. 68, 974 (1997).

[103] D.G. Nilson, M.E. Fenstermacher, R. Ellis, G. Brewis, N. Jalufka, and R.T. Snider, Rev. Sci. Instrum. 70, 738 (1999).

[104] M. Groth, M.E. Fenstermacher, C.J. Lasnier, R. Hernandez, J.M. Moller, and R.A. Sturtz, Rev. Sci. Instrum. 74, 2064 (2003).

[105] M.E. Fenstermacher, S.L. Allen, N.H. Brooks, D.A. Buchenauer, T.N. Carlstrom, et al., Phys. Plasmas 4, 1761 (1997). 
[106] M. Groth, M.E. Fenstermacher, J.A. Boedo, N.H. Brooks, D.S. Gray, et al., J. Nucl. Mater. 313-316, 1071 (2003).

[107] D.N. Hill, et al., in Proc. of 15th Int. Conf. on Plasma Phys. and Control. Nucl. Fusion Research, Seville, Spain (IAEA, Vienna, 1995) Paper IAEA-CN-60/A4-2, p.499.

[108] T.W. Petrie, D.N. Hill, S.L. Allen, N.H. Brooks, D.A. Buchenauer, et al., Nucl. Fusion 37, 321 (1997).

[109] A.W. Leonard, W.H. Meyer, B. Geer, D.M. Behne, and D.N. Hill, Rev Sci Instrum. 66, 1201 (1995).

[110] J. Schivell, G. Renda, J. Lowrance, and H. Hsuan, Rev Sci Instrum. 53, 1527 (1982).

[111] S. Konoshima, A.W. Leonard, T. Ishijima, K. Shimizu, I. Kamata, Plasma Phys. Control. Fusion 43, 959 (2001).

[112] A.W. Leonard, G.D. Porter, R.D. Wood, S.L. Allen, J.A. Boedo, et al., Phys. Plasmas 5, 1736 (1998).

[113] J.G. Watkins, C.J. Lasnier, D.G. Whyte, P.C. Stangeby, and M.A. Ulrickson, Rev. Sci. Instrum. 74, 1574 (2003).

[114] J.G. Watkins, J. Salmonson, R.A. Moyer, R. Doerner, R. Lehmer, et al., Rev. Sci. Instrum. 63, 4728 (1992).

[115] J.G. Watkins, J. Hunter, B. Tafoya, M. Ulrickson, R.D. Watson, et al., Rev. Sci. Instrum. 68, 373 (1997).

[116] R.A. Moyer, G. R. Tynan, C. Holland, and M. J. Burin, Phys. Rev. Lett. 87, 135001-1 (2001).

[117] J.A. Boedo, D. Gray, R.W. Conn, P. Luong, M.J. Schaffer, et al., Rev. Sci. Instrum. 70, 2997 (1999).

[118] D.L. Rudakov, J.A. Boedo, R.A. Moyer, S. Krasheninnikov, A.W. Leonard, et al., Plasma Phys. Control. Fusion 44, 717 (2002).

[119] D.A. Buchenauer, W.L. Hsu, J.P. Smith, and D.N. Hill, Rev. Sci. Instrum. 61, 2873 (1990). 


\section{ACKNOWLEDGMENTS}

This is a report of work supported by the U.S. Department of Energy under DE-FC02-04ER54698, DE-FG03-97ER54415, DE-FG03-01ER54615, W-7405-ENG-48, DE-FG02-04ER54758, DE-FG03-96ER54373, DE-FG02-04ER54235, and DE-AC0494AL85000. This paper summarizes the work done by the DIII-D program in this area over the past twenty years or more and includes the contributions of many members of the DIII-D Team listed in the Appendix of this volume of Fusion Science and Technology. 


\section{THE DIII-D TEAM (1986-2005) \\ AND THEIR AFFILIATIONS}

[The number following each name corresponds to the affiliation shown on page 3 of this Appendix.]

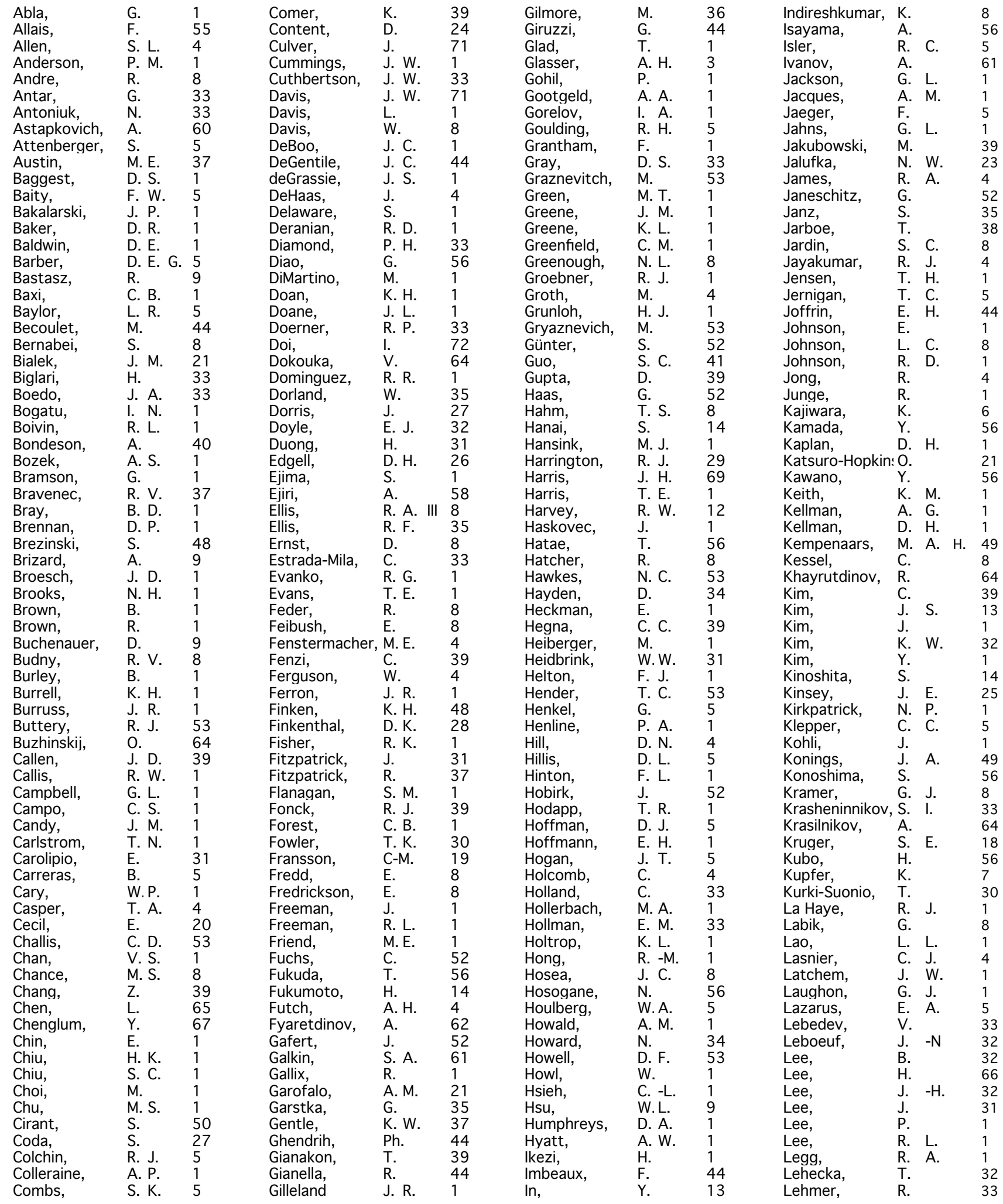




\section{THE DIII-D TEAM (1986-2005) (continued) \\ AND THEIR AFFILIATIONS}

[The number following each name corresponds to the affiliation shown on page 3 of this Appendix.]

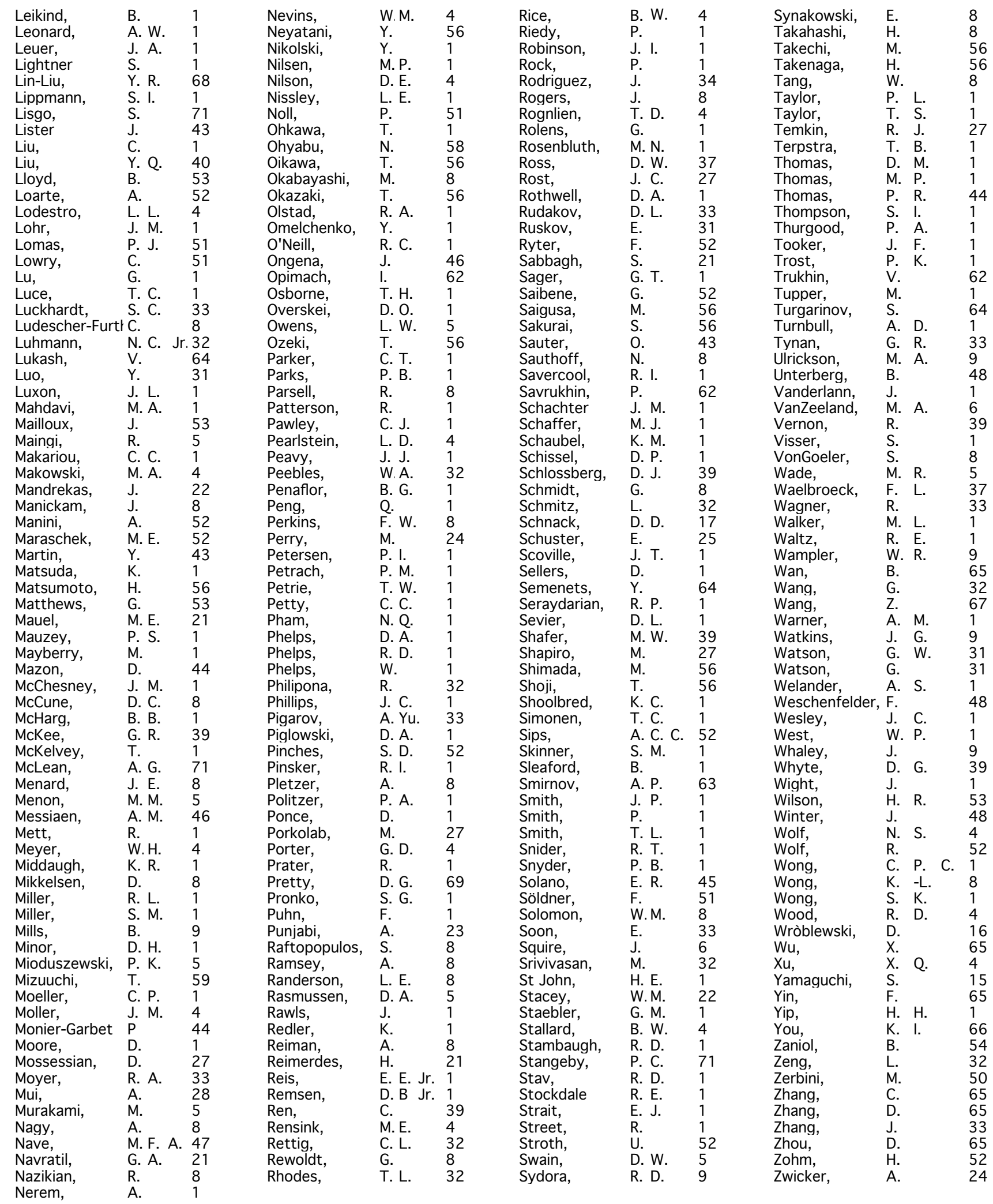




\section{AFFILIATIONS \\ OF THE DIII-D TEAM MEMBERS*}

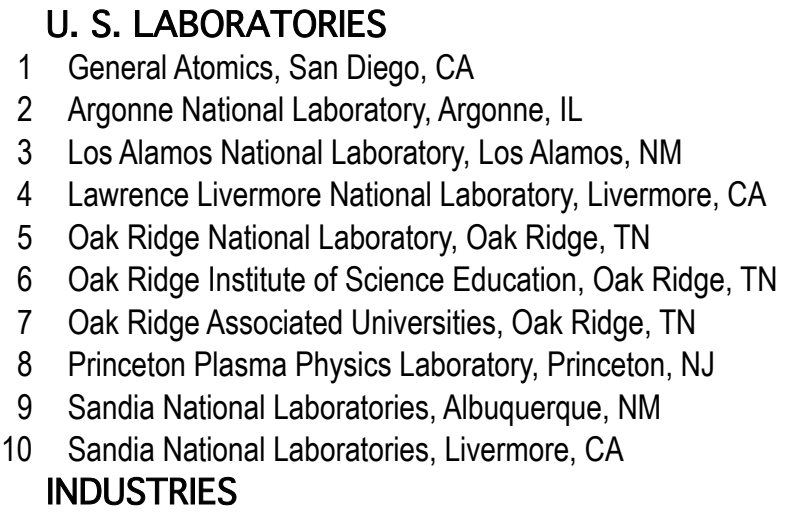

11 Communications and Power Industries, Palo Alto, CA

12 Comp-X, Del Mar, CA

13 FARTECH, Inc., San Diego, CA

14 Hitachi Ltd, Japan

15 Mitsumishi Electric Corp., Japan

16 ORINCON Corp, San Diego, CA

17 SAIC, San Diego, CA

18 Tech-X, Boulder, CO

19 Tomlab Optimization Inc. Willow Creek, CA

U.S. UNIVERSITIES

20 Colorado School of Mines, Golden, CO

21 Columbia University, New York, NY

22 Georgia Institute of Technology, Atlanta, GA

23 Hampton University, Hampton, VA

24 Johns Hopkins University, Baltimore, MD

25 Lehigh University, Bethlehem, PA

26 LLE, University of Rochester, NY

27 Massachusetts Institute of Technology, Cambridge, MA

28 Palomar College, San Marcos, CA

29 Rensselaer Polytechnic Institute, Troy, NY

30 University of California, Berkeley, CA

31 University of California, Irvine, CA

32 University of California, Los Angeles, CA

33 University of California, San Diego, CA

34 University of Illinois, Champaign, IL

35 University of Maryland, College Park, MD

36 University of New Mexico, Albuquerque, NM

37 University of Texas at Austin, Austin, TX

38 University of Washington, Seattle, WA

39 University of Wisconsin, Madison, WI

\section{EUROPE}

40 Chalmers University, Götteborg, Sweden.

41 Consorzio RFX, Padua, Italy

42 Culham Laboratory, Abingdon, UK

43 Ecole Polytechnique, Lausanne, Switzerland

44 EURATOM, CEA, Cadarache, France

45 EURATOM, CIEMAT, Madrid, Spain

46 EURATOM, Ecole Royale Militaire, Brussels, Belgium

47 EURATOM, IST, Lisbon, Portugal

48 EURATOM, Kernsforschunganlage, Jülich, Germany

49 FOM Inst., Rijnhuizen, The Netherlands

50 ENEA, Frascati, Italy

51 JET Joint Undertaking, Abingdon, Oxfordshire, UK

52 Max Planck Institute for Plasma Physics, Garching, Germany

53 UKAEA Fusion Culham Science Center, Abington, Oxon, UK

54 University of Padua, Padua, Italy

55 University of Paris, France

\section{JAPAN}

56 Japan Atomic Energy Research Insitute, Naka, Japan

57 Tsukuba University, Tsukuba, Japan

58 National Institute for Fusion Science, Toki, Japan

59 Kyoto University, Kyoto, Japan

\section{RUSSIA}

60 Efremov Institute, St. Petersburg, Russia

61 Keldysh Institute, Moscow, Russia

62 Kurchatov Institute, Moscow, Russia

63 Moscow State University, Moscow, Russia

64 Troitsk Institute, Troitsk, Russia

\section{ASIA AND AUSTRALIA}

65 Academia Sinica Institute of Plasma Physics, Heifei, China

66 Korea Basic Science Institute, Daejeon, Korea

67 Southwestern Institute of Physics, Sichuan, China

68 Dong Hua University, Haulien, Taiwan

69 Australian National University, Canberra, Australia

\section{AMERICAS}

70 CCFM, Varennes, Quebec, Canada

71 University of Toronto, Canada

72 University of Campinas, Brazil

\footnotetext{
* The affiliation at the time of the most recent collaboration with DIII-D is given.
} 